\title{
DEMAND SIDE MANAGEMENT IN SMART GRID
}

by

Ashish Trivedi - Bachelors of Electrical Engineering, Gujarat, India, 2013

\author{
A Project \\ presented to Ryerson University \\ in partial fulfillment of the \\ requirements for the degree of \\ Master of Engineering \\ in the Program of \\ Electrical and Computer Engineering \\ Toronto, Ontario, Canada, 2016 \\ (C) Ashish Trivedi 2016
}




\section{AUTHOR'S DECLARATION}

I hereby declare that I am the sole author of this project. This is a true copy of the project, including any required final revisions, as accepted by my examiners.

I authorize Ryerson University to lend this project to other institutions or individuals for the purpose of scholarly research

I further authorize Ryerson University to reproduce this project by photocopying or by other means, in total or in part, at the request of other institutions or individuals for the purpose of scholarly research.

I understand that my project may be made electronically available to the public. 


\title{
DEMAND SIDE MANAGEMENT IN SMART GRID \\ By - Ashish Trivedi \\ Degree - Master of Engineering \\ Program - Electrical and Computer Engineering, 2016 \\ Ryerson University - Toronto
}

\begin{abstract}
In this project report a Demand Side Management system is proposed which helps to reduce the peak demand on the grid by motivating the consumer to shift or reduce the load consumption. The proposed technique helps to manage the operating time of both schedulable and non-schedulable loads through consumer's interaction.

The consumers can save money by operating them in lower price periods. However, inspite of its privileges this approach has the tendency to accumulate more load at low electricity price time as the load is being shifted from other periods. Therefore, an addition optimization is used to formulate the second peak-generated problem by defining certain constraints for the consumption.
\end{abstract}

For non-schedulable loads an optimizing scheme is proposed where the utility controls the operation of the loads like refrigeration, HVAC system with respect to the consumer comfort levels. The simulation result validates the reduction in the peak demand on the grid. 


\section{ACKNOWLEDGEMENT}

It is with deep appreciation that I am writing this to express my special thanks of gratitude to my supervisor Dr. Kaamran Raahemifar who gave me the excellent opportunity to do this wonderful research and project on the topic of DEMAND SIDE MANAGEMENT. I greatly admire the guidance and supervision given to me by my supervisor.

Secondly I would also like to thank my parents and friends who helped me a lot in finalizing this project within the limited time frame. 


\section{TABLE OF CONTENTS}

INTRODUCTION

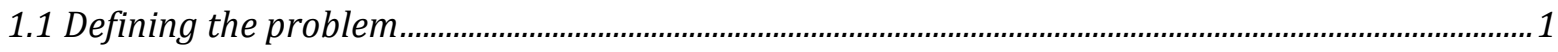

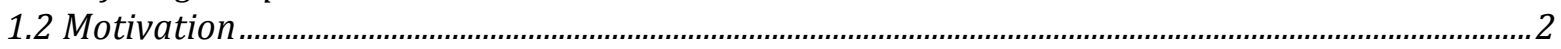

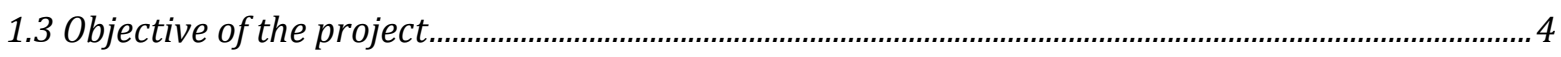

1.4 Contributions

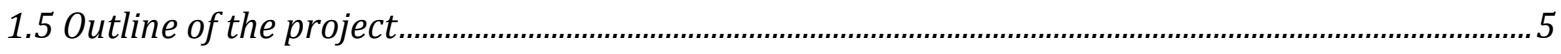

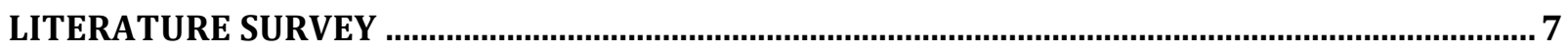

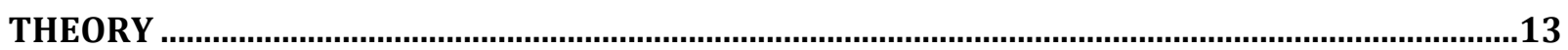

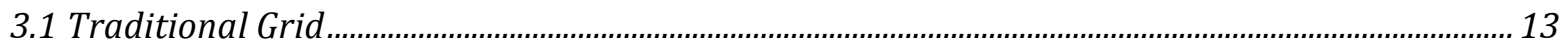

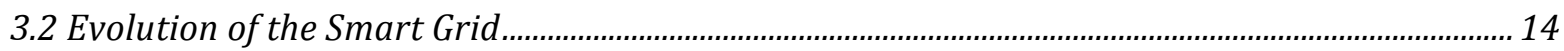

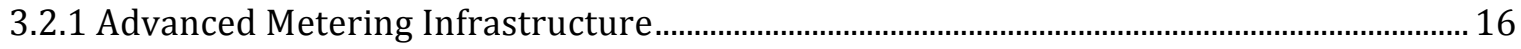

3.2.2 Home Energy Management System (HEMS): Smart Home..................................................... 17

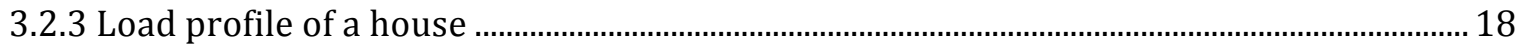

3.2.4 Time of Use Tariff: Time-based pricing ................................................................................. 19

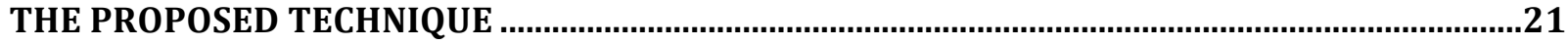

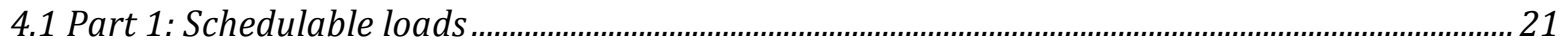

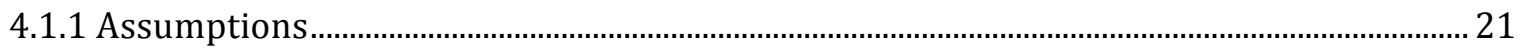

4.1.2 Optimization formulation and algorithm .................................................................................. 22

4.1.3 Optimizing the second peak demand generated on the grid ................................................. 25

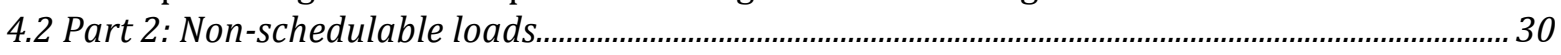

4.2.1 Assumptions and General Explanation …………................................................................... 30

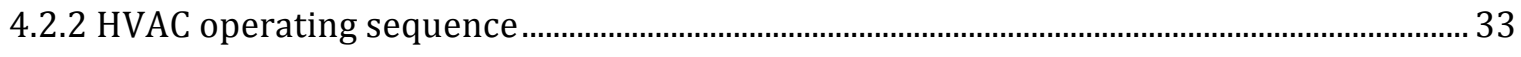

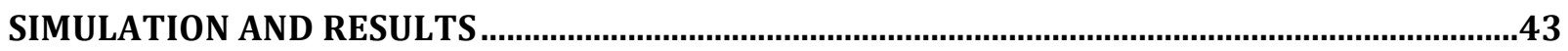

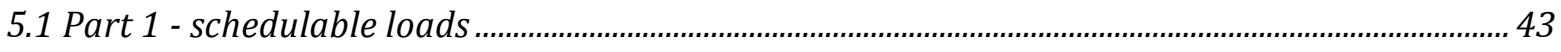

5.1.1 Case 1 - Consumer sets a cost constraint.............................................................................. 43

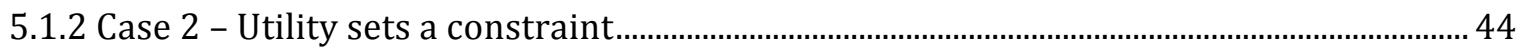

5.1.3 Case 3 - Hybrid case where both the utility and consumer set a constraint ..................... 45

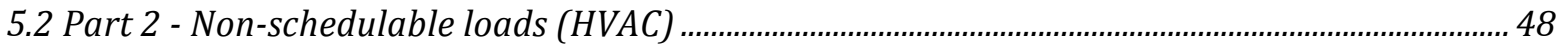

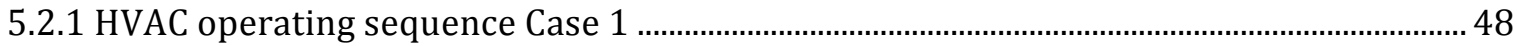

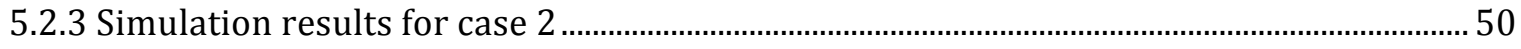

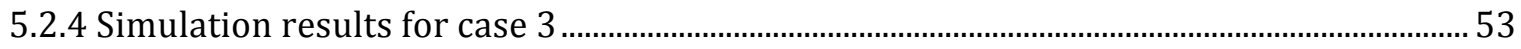

CONCLUSION

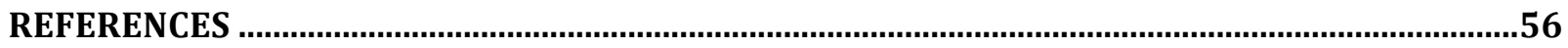




\section{TABLE OF FIGURES}

Figure 1 - Graphical representation of Peak Clipping, Load Shifting and Valley filling

Figure 2 - Operating scheme of ILP technique [21]

Figure 3 - Heuristic approach to the DSM strategy [22]

Figure 4 - Game Theory approach where consumers or users interact with each other 9 [23]

Figure 5 - Flowchart for Vickrey-Clarke-Groves mechanism [26]

Figure 6 - Transformation of traditional grid into smart grid [29]

Figure 7 - Flowchart explaining the basic overview of DSM process

Figure 8 - Architecture of the HAN and AMI [37]

Figure 9 - Time of Use pricing chart [12]

Figure 10 - 24 intervals representing 24 hours in a day

Figure 11 - Flowchart explaining the brief process of DSM

Figure 12 - Traditional load profile (non-optimized)

Figure 13 - Optimized load profile through DSM

Figure 14 - Flow chart explaining the case 1 in part 1 . Here the consumer sets a constraint

Figure 15 - Flowchart explaining case 2 in part 1 where utility sets the constraint

Figure 16 - Flowchart explaining the case 3 in part 1. This is a hybrid case where the utility ad consumer both can set up a constraint

Figure 17 - Schematic of a house showing possible area for heat loss [38]

Figure 18 - Traditional non-optimized HVAC run time load profile with base load

Figure 19 - Optimized load profile of the HVAC system where the load is distributed 


\section{LIST OF TABLES}

Table 1 - Electricity pricing for different periods throughout the day

Table 2 - HVAC operation sequence for all 20 houses

Table 3 - Random allocation of size of the house which are small(S), medium(M), and $\operatorname{large}(\mathrm{L})$

Table 4 - The table shows the HVAC operating sequence for non-optimized approach 48

Table 5 - The table shows the operating sequence of the HVAC system after implementing the optimization formulation

Table 6 - Part 2 case 2 non-optimized (traditional) way of HVAC operation

Table 7 - Part 2 case 2 optimized approach where the load is distributed over larger time 51

Table 8 - Pink table - Randomly allocated size of the house, Green table - Houses sorted in ascending order of temperature reading and Blue tables below show the grouping of the houses. 


\section{LIST OF GRAPHS}

Graph 1 - Case 1 of part 1 where consumer sets the constraint 43

Graph 2 - Case 2 of part 1 where the utility sets the constraint 44

Graph 3 - Case 3 of part 1 . This is a hybrid case where both the consumer and utility set a $\begin{array}{ll}\text { constraint } & 46\end{array}$

Graph 4 - Load profile comparison of traditional and optimized approach 49

Graph 5 - Load profile comparison of traditional way of HVAC operation and optimized approach of HVAC operating sequence for Part 2 case 2

Graph 6 - Load profile comparison of traditional way of HVAC operation and optimized approach of HVAC operating sequence for Part 2 case 3 


\section{ABBREVIATION}

MD/PD - Maximum Demand / Peak Demand

EC - Electricity Cost

PAR - Peak to Average Ratio

DSM - Demand Side Management

DR - Demand Response

HVAC - Heat Ventilation and air conditioning

HEMS - Home Energy Management System

ToUT - Time of Use Tariff

$\mathrm{CO}_{2}-$ Carbon Di-Oxide

GW - Giga Watt

MW - Mega Watt

HAN - Home Area Network

AMI - Advanced Metering Infrastructure

CDMS - Central Data Management System

BTU - British Thermal Unit

VCG - Vickrey-Clarke-Groves

ECC - Energy Consumption Controller

ECS - Energy Consumption Scheduler 


\section{Chapter - 1}

\section{INTRODUCTION}

\subsection{Defining the problem}

As the world develops economically with the increase in population, the demand for electricity will also increase that eventually increases Peak Demand (PD) on the grid. To ensure power systems reliability and efficiency it is very important to generate and supply enough electricity to meet the consumer's demands which also means the total installed capacity of the grid should be more than PD [1].

Expanding the existing grid infrastructure to cope up with the rapidly increasing electricity demands gives rise to the following problems.

- It shall increase the price of the electricity delivered to the end consumer, as new investments are needed to install more number of generators and distribution systems to increase the capacity of the grid.

- Installation of non-renewable generating systems contributes towards increase in pollution and carbon footprints hence depleting the environment.

- Expanding the power network makes the grid more prone to faults, complex to operate and eventually reducing the operating efficiency and reliability.

If the demands are not met at any point of time, the electrical grid might collapse creating a huge chaotic situation and result in a blackout or brownout which can completely shut down manufacturing process at companies and some critical infrastructure sectors like telecommunication networks, financial industry, hospitals and supplies such as water, heat and cooling.

Furthermore as the load/demand on the grid increases it might lead to frequent power blackouts, that also has a significant impact on the nation's economic loss if the grid is not expanded accordingly. The rapidly growing demand for electrical energy is ceaseless. Hence, 
there is a need to upgrade or expand the electrical power infrastructure.

The traditional way of meeting the PD is done by increasing the capacity of the grid by installing more generation and transmission systems, however if the PD increases beyond the available capacity, utilities resort to load shedding by de-energizing some feeders [1]. This would leave a portion of the city in dark. Since the PD on the grid only appears for a small portion of the day it would be more convenient and economical if the PD during the day can be modified, reduced or shifted by scheduling the loads and the act of encouraging the consumers in doing so is termed as Demand Response (DR). The encouragement can be compulsory or can be provided by the time of use tariff (ToUT) based DR program. This in whole shall reduce the overall PD [18].

The grid is getting de-centralized as it transforms towards smarter grid. Smart grids [13] [14] can be defined as a unique combination of technologies like automation, computation and communication applied on monitoring control and maintenance of electric network. Smart grids use two-way interaction technology where electricity and information on consumer behavior and the loads is gathered and shared between the consumer and the utilities [15].

A smart grid also enables newer technologies to be integrated in the grid such as plug-inelectric-vehicle, wind and solar energy. The loads, energy storage and distributed generation will soon be managed as a micro grid instead. In this phenomenon the consumer will have the opportunity to control their power usage as well as reduce their cost. In some situations, this can even lead to consume more electricity, but pay less for it. [16] [17]

With the advent of smart grid, utilities can now send real-time electricity price signals to the consumers and receive consumer's load consumption.

\subsection{Motivation}

To keep up with the constantly changing energy demands utilities must turn power plants on/off depending on the amount of electricity needed at certain times of the day. The cost to deliver electricity depends on the time of the day it is used. 
Electricity is more costly to deliver at peak times because additional, less efficient power plants must operate to meet the PD on the grid. These additional power plants operated during the peak times not only increases the electricity cost but also significantly contributes in polluting the environment by emitting carbon dioxide and other green house gases and also more and more amount of fossil fuel is being used to feed these power plants to generate power.

After this power is generated the distribution system has to efficiently transmit the electricity from the power plants to the consumers. The distribution system is subjected to stress during the PD periods as the system is operating at or near its threshold capacity, which eventually reduces the lifespan of the grid. Future investments are needed to constantly improve and maintain the grid.

At each instant of time throughout the day the amount of electricity generated must be equal to the consumption across the entire grid. As discussed earlier, the PD on the grid only appears for a certain time of the day. It is very important to manage the PD, as it would help reduce pollution and new investments, promote proper utilization of the electricity generation and transmission systems.

With the advent of smart grid technology, utilities can now send real-time electricity price signals to the consumers also known as ToUT and receive consumer's load consumption. With this exchange of information the consumer can shift or schedule their loads from peak hours to off-peak hours to help reduce the PD on the grid as well as save money on electricity bills. This also helps grid operators or utilities to see and manage electricity consumption in real time. This approach reduces the number of blackouts and lowers the need to generate more power to meet the PD hence reducing the pollution in the environment and also reduces the need for future investments. This phenomenon is known as Demand Side Management (DSM). DSM screens, plans and implements different approaches and methods that are designed to encourage the consumer to consume less electricity during the peak hours or perform load shifting in order to shape the load profile of the grid. DSM also helps to properly utilize the present available resources without investing for new infrastructure. 


\subsection{Objective of the project}

The main aim of the project is to manage the consumer end load such that the load profile can be shaped and the PD on the grid can be reduced. Reducing the PD minimizes the problems created by it. The figure below shows how a load curve can be reshaped using demand side management approach to reduce the PD.
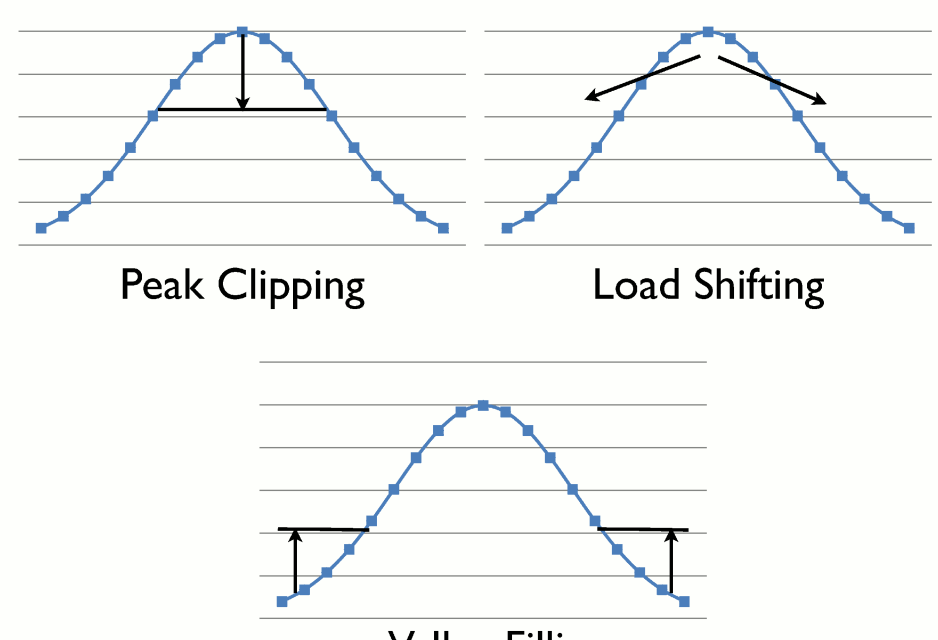

Valley Filling

Figure 1 - Graphical representation of Peak Clipping, Load Shifting and Valley filling [19]

Peak clipping [19] [20] is done by the utilities through shutting down some feeders, but in doing so many consumers end up staying in dark. Load shifting [20] can be done by encouraging consumers to shift their loads from on-peak periods to off-peak periods. A demand response or demand side management approach has been presented in this report, which motivates the consumer to schedule their loads or shift them to off-peak periods, hence reducing the peak load on the grid. Using Smart Grid technology Smart grids use two-way interaction technology where information on consumer behavior and the system is gathered and shared between the consumer and the utilities companies. The loads, energy storage and distributed generation will soon be managed as a micro grid. In this phenomenon the consumer will have the opportunity to control their power usage as well as reduce their cost of electricity consumed. In some cases, this can even lead to consume more electricity, but pay less for it [16] [17]. 


\subsection{Contributions}

In this project Demand Side Management technique is proposed to cope with rising electricity demand. With the advent of smart grid the utility and the consumer both can exchange real time information and energy. In this presented approach the consumer is encouraged to shift their loads or even to reduce their consumption. The consumers are given a day ahead electricity price signals and looking at them they can schedule their loads to save money and eventually this will help the utility to reduce the peak demand on the grid.

The load profile is categorized into two categories in this method, which is a) schedulable load and b) non-schedulable loads. The Part 1 in this project optimizes the operating time of schedulable loads to reduce the Peak Demand on the grid where the electricity price signals are given to the consumers for scheduling their loads for the next 24-hours and different cases are presented to cope up with different consumer behavior. The Part 2 optimizes the run-time of HVAC system, which is a non-schedulable load, as the consumer cannot shift this load because it is temperature dependent.

The world can be a better place as the implementation of this technique helps reduce pollution i.e. $\mathrm{CO}_{2}$ emissions. Avoids additional investments to expand the existing electrical grid. It helps the consumers to manage their load consumption and save on electricity bills.

\subsection{Outline of the project}

Chapter 1 gives an introduction to the topic. It explains what are the problems faced how is it created. It also throws light on motivation and objective of the project.

Chapter 2 explains the literature survey where different papers are analyzed and compared with this project approach.

Chapter 3 is the theory portion of the project where the whole topic is explained in detailed. It 
also presents a brief idea of solving the problem mentioned in chapter 2 .

Chapter 4 presents the proposed technique where the optimization formulation is explained in detailed steps. Different scenarios are considered to solve the problem.

Chapter 5 is the simulation and results section where the implementation is shown with proper comparison of the results with traditional way. 


\section{Chapter - 2}

\section{LITERATURE SURVEY}

A survey was done to understand different approaches to reduce the PD on the grid. In paper [21] a consumption scheduling method for home area load management in smart grid using integer linear programming (ILP) technique is shown. The objective of this approach is to reduce the PD to attain a balanced daily load profile. This approach enables the consumer to schedule the optimal run time for power-shiftable loads and time-shiftable loads respectively. In Figure $2[21]$ we can see the basic operation scheme of the system.

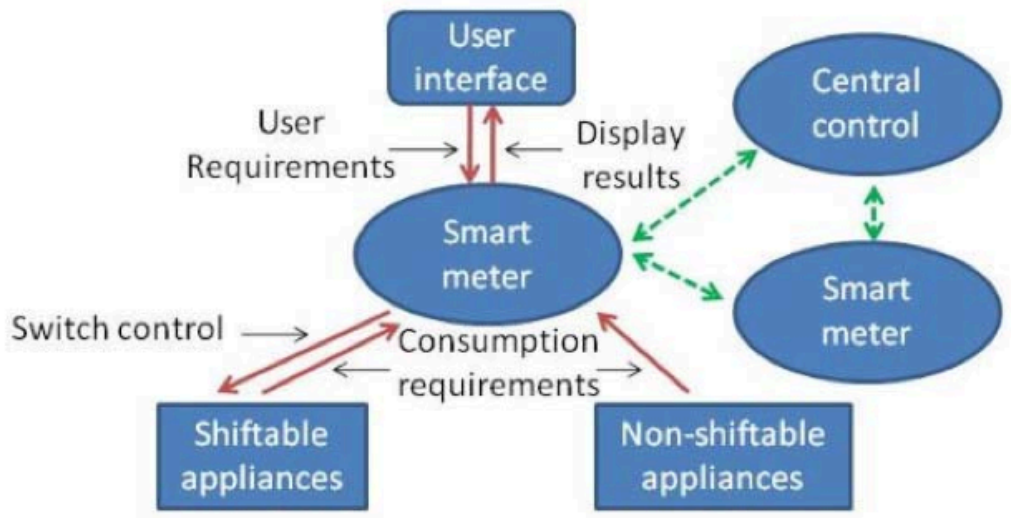

Figure 2 - Operating scheme of ILP technique [21]

This approach helps to reduce the PD on the grid. However the disadvantage of this approach is as the consumer is given full command on scheduling the loads a second peak load might be generated in the load profile as majority of the consumers will shift their loads from high price periods (ON-Peak) to lower price periods (OFF-Peak) and also the operation of nonschedulable loads like HVAC system or refrigeration can only be done when the load demand on the grid is less hence it might not achieve consumer's comfort level every time. 
In [22] a heuristic optimization approach is presented. It does optimize the load profile as it reduces the PD on the grid but at the same time the consumers are given full command to schedule their loads a day ahead. This in fact leads to the same issue of second peak generation in the load profile. More focus is given to the schedulable loads. There is no optimization approach for the non-schedulable loads. Hence if the mass of the consumers wakes up at or around the same time and turn the HVAC system $\mathrm{ON}$ by increasing or decreasing the temperature then the grid might see another peak demand. Optimization of both the schedulable and non-schedulable loads is must to reduce the PD on the grid. The figure 3 [22] shows the schematic operation of Heuristic optimization approach.

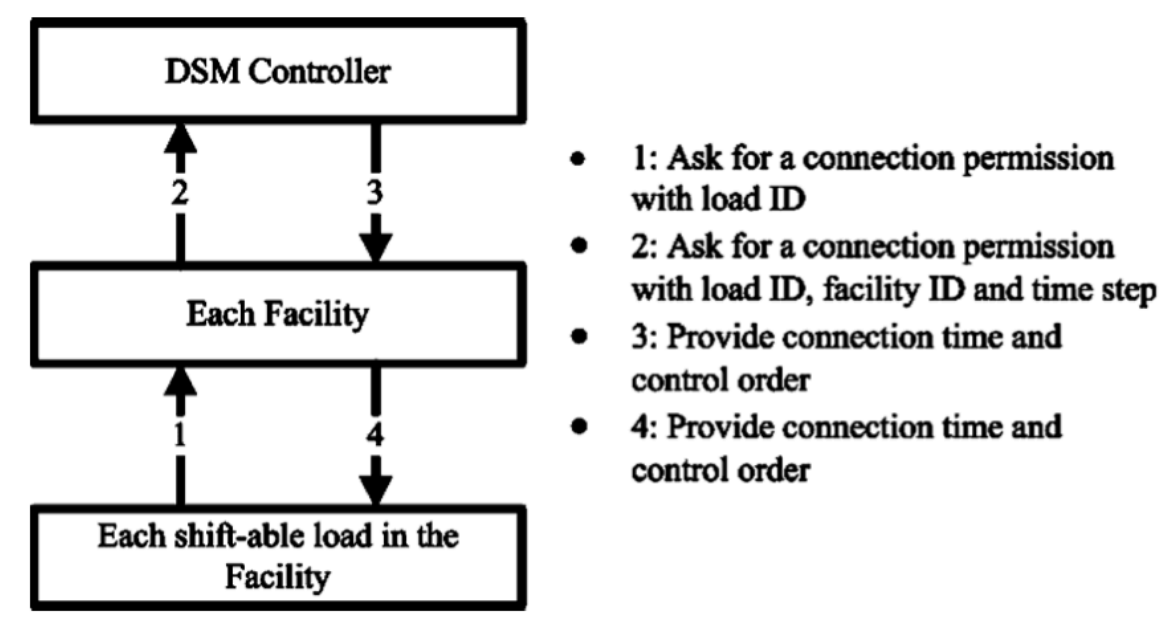

Figure 3 - Heuristic approach to the DSM strategy [22]

In [23]-[25], a game-theory based optimization approach is presented to schedule the run time of the loads. In this model consumers are players and their strategies are their daily scheduling loads. Ideal performance in terms of electricity cost minimization is achieved at Nash equilibrium of electricity consumption scheduling game. The approach here considers a usual scenario where a single utility company provides electricity to many different consumers. This approach systematically manages the load schedule and shifts them to reduce the overall energy consumption cost. The Figure 4 [23] explains the concept of this approach. 


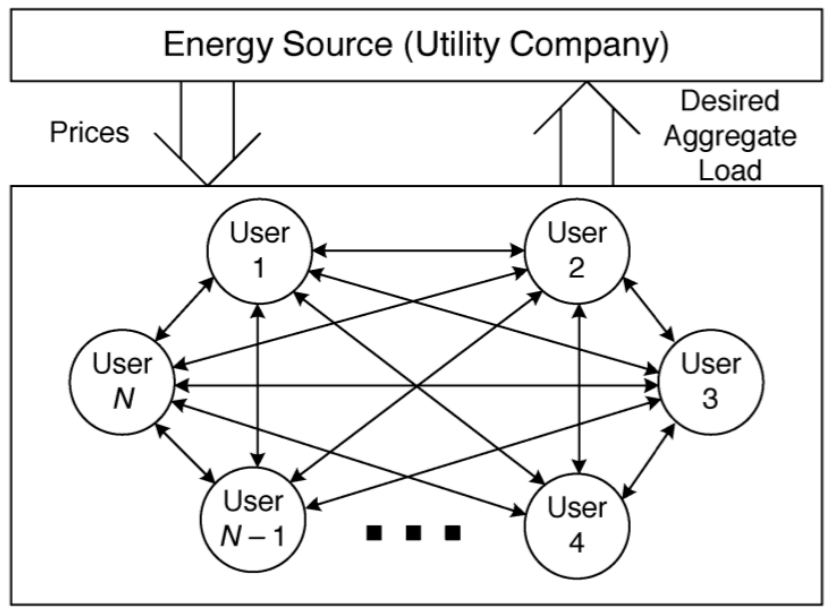

Figure 4 - Game Theory approach where consumers or users interact with each other [23]

Most of the DSM approaches focuses on the interactions between the utility company and each user, the basis of game theory design are the interactions between the consumers. In this method it requires only some limited message exchanges between the consumers when each of them tries to increase their benefits in a game theoretic environment.

In order to motivate the consumers to act in a way to reduce the energy cost a smart pricing tariff such that the interactions among the users automatically lead to an optimal aggregate load profile at the equilibrium of an energy consumption scheduling game is proposed.

Energy Consumption Scheduler (ECS) is installed in smart meters for scheduling the loads in a house. It practices a distributed algorithm to find the feasible schedule for each user. This approach considers two types of loads, shiftable and non-shiftable. Shiftable loads e.g. washing machine and dryer. Non-shiftable appliances are those that are always in operating state for a long time period e.g. fridge and HVAC system. ECS only schedules the shiftable loads.

In the game theory approach the ECS does not manage the run time or operation of Nonschedulable loads such as HVAC system or refrigeration. The other disadvantage of this approach is that the consumers are provided with majority of the command to manage their load so incase if a large portion of consumers were to schedule or shift their loads from ONPeak periods to OFF-Peak periods then it will lead to the generation of second peak. 
In [26] Vickrey-Clarke-Groves (VCG) method increases the social well being i.e. the difference between aggregate utility function of all consumers and total electricity consumption cost. It is considered that each consumer has installed Energy Consumption Controller (ECC) device in its smart meter for scheduling the household appliances. ECC schedules the load. VCG method enables efficient energy consumption among all consumers.

In this approach, each consumer provides his/her energy demand to the utility. Once the utility receives the overall energy demand for the day ahead from all the consumers through the ECC, the utility declares electricity payment for each consumer. In this way, VCG method reduces the PD on the grid.

Load profile can be divided into two categories i.e. must-run loads and controllable loads. Must-run loads are also known as non-schedulable loads such as HVAC system or refrigeration are always in ON state throughout the day. The controllable loads are the loads where operation can be shifted and housed in different time slots throughout the day according to demand on the grid. Figure 5 [26] summarizes this approach in a flowchart.

Consumers reveal their energy demand for next 24 hours to the utility through the Energy Consumption Controller

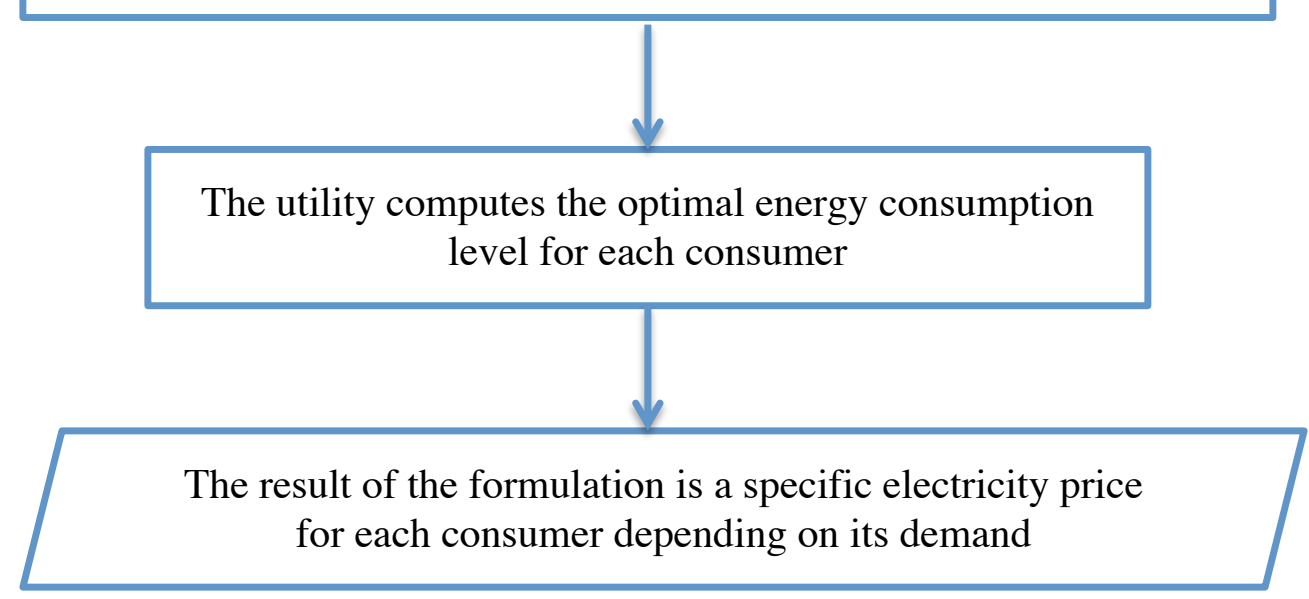

Figure 5 - Flowchart for Vickrey-Clarke-Groves mechanism [26] 
Using this approach might help to avoid generation of a second peak on the grid as different electricity prices are send to the consumers, but sending specific prices to each consumers makes the formulation complex. However it might not solve the problem completely as the consumers still have good amount of command to manage their loads. Also this approach does not manage the Non-schedulable loads. Hence the loads like HVAC system, refrigeration will add to the PD on the grid.

To summarize this chapter we saw different approaches and methods of demand side management to reduce the PD on the grid. None of the optimization approaches were able to manage the non-schedulable loads. These loads are HVAC system, refrigeration, which are in the ON state for most of the time and does contribute in increase or generation of PD. Such loads cannot be shifted or scheduled, as they are temperature dependent and runs according to the consumer comfort level.

For schedulable loads approaches like in ILP technique, Heuristic optimization method and Game-Theory mechanism encourages the consumer to shift their loads to lower electricity price periods. In approaches like ILP and Heuristic optimization each and every consumer is directly connected to the utility. But in case of Game Theory method consumers communicate with each other like players and this group of consumers as a whole interacts with the utility. These methods does help to reduce the PD on the grid and as the consumers are running the loads in low cost intervals they will save on electricity bills. But as majority of the consumers shift their load to lower price intervals it might lead to generation of a second peak demand on the grid.

In mechanism like Vickrey-Clarke-Groves the consumer reveals the energy demand to the utility and from this demand the utility computes the best energy consumption level for each consumer by giving them different electricity price signals. This helps to reduce the chances of generating a second peak. However as the consumer is still having the command to manage their loads, so there are slight chances of generation of a second PD on the grid. 


\begin{abstract}
Also these approaches consider non-schedulable loads as base loads or loads that are always in the ON state. There is a need to optimize the run time of non-schedulable loads to reduce the PD and optimize every single load at the consumer end. In chapter 5 a demand side management method has been proposed which manages both schedulable and non-schedulable loads in a house. Different cases have been presented to cope up with different scenarios in day-to-day life of a consumer.
\end{abstract}




\section{Chapter - 3}

\section{THEORY}

\subsection{Traditional Grid}

The first AC power grid system was installed in 1886 [27]. At that time, the grid was a centralized unidirectional system of electric power transmission, electricity distribution, and demand-driven control.

In the 20th century local grids grew over time, and were eventually interconnected for economic and reliability reasons. By the 1960s, the electric grids of developed countries had become very large, mature and highly interconnected, with thousands of 'central' generation power stations delivering power to major load centers via high capacity power lines which were then branched and divided to provide power to smaller industrial and domestic users over the entire supply area.

The topology of the 1960s grid was a result of the strong economies of scale: large coal, gas and oil-fired power stations in the $1 \mathrm{GW}(1000 \mathrm{MW})$ to $3 \mathrm{GW}$ scale are still found to be cost effective, due to efficiency boosting features that can be cost effective only when the stations becomes very large. Power stations were located strategically to be close to fossil fuel reserves (either the mines or wells themselves, or else close to rail, road or port supply lines). Siting of hydroelectric dams in mountain areas also strongly influenced the structure of the emerging grid. Nuclear power plants were sited for availability of cooling water. Finally, fossil fuel-fired power stations were initially very polluting and were sited as far as economically possible from population centers once electricity distribution networks permitted it. By the late 1960s, the electricity grid reached the overwhelming majority of the population of developed countries, with only outlying regional areas remaining 'off-grid'.

Metering of electricity consumption was necessary on a per-user basis in order to allow appropriate billing according to the (highly variable) level of consumption of different users. Because of limited data collection and processing capability during the period of growth of the 
grid, fixed-tariff arrangements were commonly put in place, as well as dual-tariff arrangements where night-time power was charged at a lower rate than daytime power. The motivation for dual-tariff arrangements was the lower night-time demand. Dual tariffs made possible the use of low-cost night-time electrical power in applications such as the maintaining of 'heat banks' which served to 'smooth out' the daily demand, and reduce the number of turbines that needed to be turned off overnight, thereby improving the utilization and profitability of the generation and transmission facilities. The metering capabilities of the 1960s grid meant technological limitations on the degree to which price signals could be propagated through the system.

Through the 1970s to the 1990s, growing demand led to increasing numbers of power stations. In some areas, supply of electricity, especially at peak times, could not keep up with this demand, resulting in poor power quality including blackouts, power cuts, and brownouts. Increasingly, electricity was depended on for industry, heating, communication, lighting, and entertainment, and consumers demanded ever-higher levels of reliability.

Towards the end of the 20th century, electricity demand patterns were established: domestic heating and air-conditioning led to daily peaks in demand that were met by an array of 'peaking power generators' which were less efficient and more polluting generators that would only be turned on for short periods each day. The relatively low utilization of these peaking generators (commonly, gas turbines were used due to their relatively lower capital cost and faster start-up times), together with the necessary redundancy in the electricity grid, resulted in high costs to the electricity companies, which were passed on in the form of increased tariffs

The electrical grid is getting less reliable, less efficient power plants are needed to match up the peak demand on the grid causing a significant contribution to the green house gases and polluting the environment, to cope up with the increasing demand for the electricity the electrical grid needs to grow progressively in capacity, it clearly proves that there is a need for transition.

\subsection{Evolution of the Smart Grid}

Our current electric grid was built in the 1890s and improved upon as technology advanced through each decade. Today, it consists of more than 9,200 electric generating units with more 
than 1 million MW of generating capacity connected to more than 300,000 miles of transmission lines. Although the electric grid is considered an engineering marvel, we are stretching its patchwork nature to its capacity.

To move forward, we need a new kind of electric grid, one that is built from the bottom up to handle the groundswell of digital and computerized equipment and technology dependent on it and one that can automate and manage the increasing complexity and needs of electricity in the 21st Century. This gives birth to a newer grid technology know as "The Smart Grid” [28].

The Smart Grid represents an unprecedented opportunity to move the energy industry into a new era of reliability, availability, and efficiency that will contribute to our economic and environmental health. During the transition period, it will be critical to carry out testing, technology improvements, consumer education, development of standards and regulations, and information sharing between projects to ensure that the benefits we envision from the Smart Grid become a reality. Figure 6 [29] shows the transformation of the Grid over time.

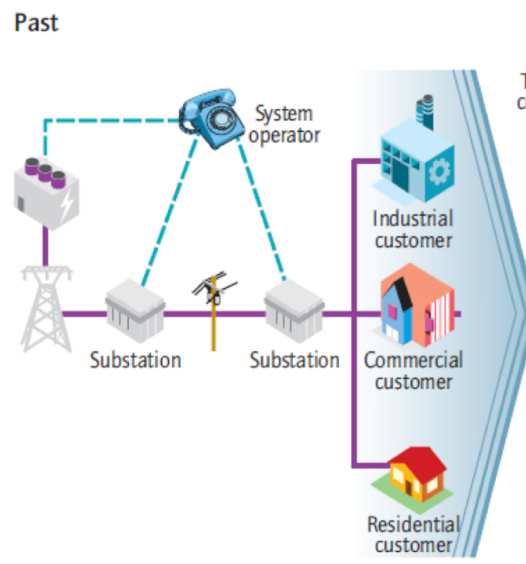

Present

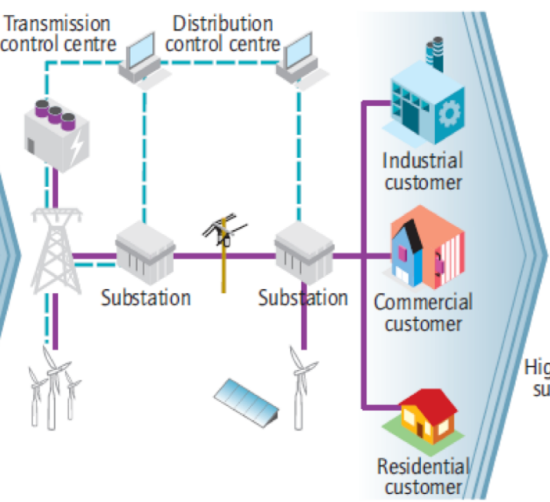

- Electrical infrastructure
Future

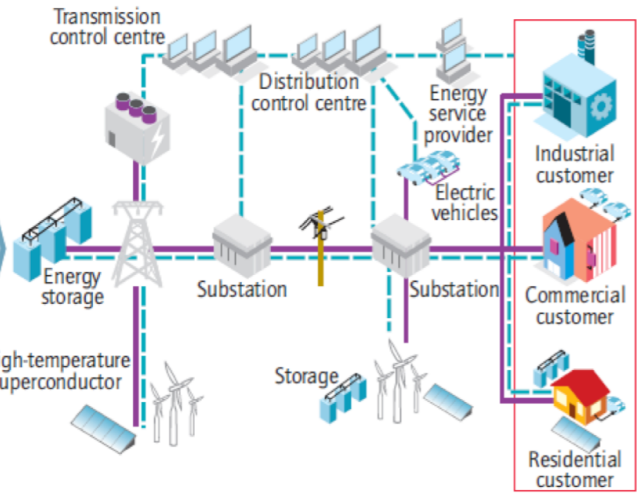

Communications

Figure 6 - Transformation of traditional grid into smart grid [29]

The benefits associated with the Smart Grid include:

- More efficient transmission of electricity

- Quicker restoration of electricity after power disturbances

- $\quad$ Reduced operations and management costs for utilities, and ultimately lower power costs 
for consumers

- $\quad$ Reduced peak demand, which will also help lower electricity rates

- Increased integration of large-scale renewable energy systems

- Better integration of customer-owner power generation systems, including renewable energy systems

- Improved security of the system

The Smart Grid infrastructure mainly consists of follow elements for demand response programs

- Smart Meters also known as Advanced Metering Infrastructure (AMI), and

- Distribution automation which also includes Home Energy Management System (HEMS)

\subsubsection{Advanced Metering Infrastructure}

Advanced Metering Infrastructure consists of a network of smart meters that are connected with the utility through Internet domain [30] [31]. This helps the utilities to receive real-time energy consumption from the consumer and send real-time electricity price signals. Since traditional DR is often done manually, it is difficult for the end consumers to keep a track on the hourly price signals and react to them by scheduling their appliance usage, whereas they do not have sufficient knowledge and time [32]-[34]. Thus, automated DR is necessary for attracting more consumers to take part in DR/DSM programs. Obviously it is impossible to benefit from all of its various merits without extensive and pervasive participation of the demand side. Hence, energy management system has been presented to control home power consumption with regards to DR signals, real-time price, consumer preferences and specific comfort level. The two technologies named as building automation and smart metering enables the demand side optimization.

Considering the house to be a smart home consisting of a smart controller, where all the appliances or loads has the capability to communicate with each other. The smart controller acts as an interface between smart meters and the appliances as the loads are connected to the 
smart meter through the smart controller. This whole arrangement is known as Home Energy Management System (HEMS). The flowchart below explains the process well. The price signals sent by the utilities are for the day ahead i.e. for next 24 hours.

Utility sends price signals with

electricity to all the smart meters

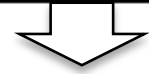

Smart meters passes this information to the smart controller which helps the consumers to control or monitor their power consumption profile, appliance usage schedule and etc. through an in-home display(computer, tablet or smart phone)

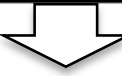

The consumers would schedule their loads according to the price signals they received to save on electricity bills

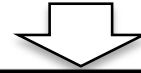

The load consumption scheduled by the consumer is stored in the smart controller so that it can give ON/OFF command to the load depending on the time it has been scheduled

Figure 7 - Flowchart explaining the basic overview of DSM process

\subsubsection{Home Energy Management System (HEMS): Smart Home}

A HEMS consists of smart appliances or loads that are connected with each other through a network called Home Area Network (HAN) [35]. The HAN connects the smart appliances with the smart controller [36]. The consumer can see the electricity price signals and schedule the run time of all the appliances such that he/she will save on electricity bills by scheduling the schedulable loads in off-peak periods. The smart controller will run the loads when the schedule time arrives. This will have a direct impact on reduction of the PD on the grid. These smart devices can be scheduled or controlled over the web or even through a smart TV, computer or a tablet. The figure [37] above shows the operating scheme of the Smart Grid infrastructure. 


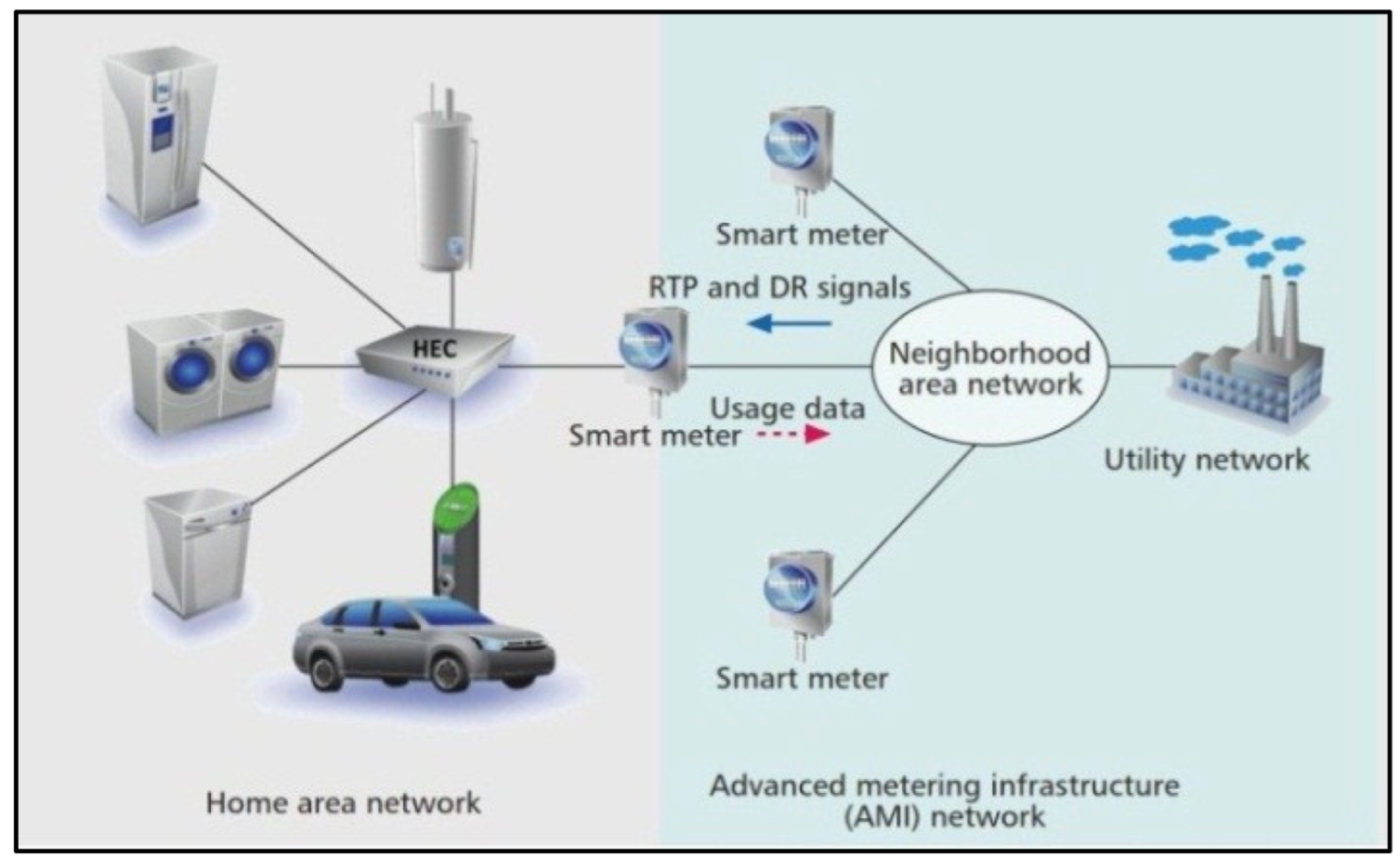

Figure 8 - Architecture of the HAN and AMI [37]

\subsubsection{Load profile of a house}

The loads at consumer end are divided into two categories

\section{- Schedulable loads -}

The loads that can be operated automatically whose operation can be delayed or shifted earlier or later by few time slots without much impact on the consumer comfort level are known as schedulable loads. For example plug in hybrid electric vehicle, dishwasher, washing machine. Such loads can be easily scheduled in the off-peak periods as they turn ON for couple of hours.

\section{- Non-schedulable loads -}

These type of loads include temperature dependent loads such as HVAC (heating ventilation 
air conditioning), refrigerator as they are almost in running state the power consumption of these loads must be supplied immediately regardless of the scheduling done to maintain the consumer's comfort level. These loads are temperature dependent so they don't have a specific time frame of operation.

\section{- Base line loads -}

It includes loads such as lights, fans, TVs, vacuum cleaner etc. that need to be supplied with energy as soon the consumer wants to turn them ON, so they are considered as base line loads.

\subsubsection{Time of Use Tariff: Time-based pricing}

Time-based pricing is an approach where the utility or electricity provider, may vary the price depending on the time-of-day the electricity is delivered [11]. A day, which comprises of 24 hours, is divided into different time-intervals depending on the demand on the grid and every interval has different electricity prices [12]. Usually there are three time-intervals, depending on the electricity demand.

- Off-peak period - When the demand on the grid is least.

- Peak or on-peak period - When the demand on the grid is maximum.

- Mid-range period - When the demand on the grid is intermediate.

Weekdays have different electricity prices as well as different time-intervals throughout the day, because during weekdays the grid has industrial and commercial loads in addition to other loads. 

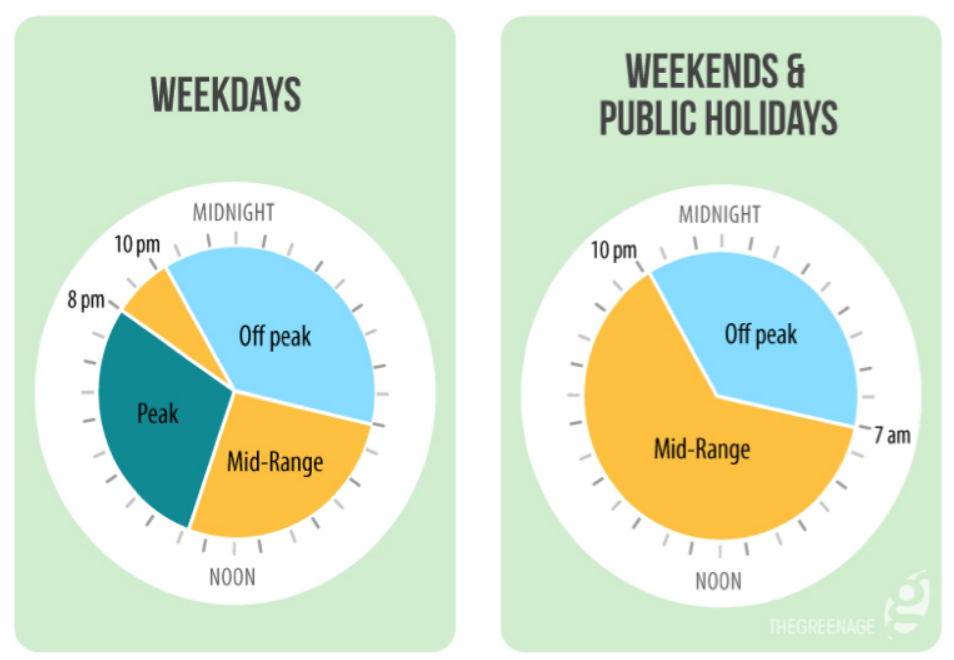

Figure 9 - Time of Use pricing chart [12] 


\section{Chapter - 4}

\section{THE PROPOSED TECHNIQUE}

There are two parts of this chapter. The first part explains how the schedulable loads can be managed using HEMS, electricity price signals. Different cases have been presented to make the approach more flexible and easy to implement for different scenarios occurring in the dayto-day life. However this part has a drawback as it cannot manage the temperature dependent or time dependent loads such as the HVAC system, refrigerator. Keep this drawback in mind the second part has been designed to optimize the operation of the non-schedulable loads.

The second part explains management of the non-schedulable loads as they cannot be shifted or reduced like other loads. The approach defined, expands the operation or the run time of these loads over a span of time making sure that the consumer comfort levels are met as the same time reduce the peak demand on the grid.

\subsection{Part 1: Schedulable loads}

\subsubsection{Assumptions}

- Three loads are considered in the optimization formulation for a house.

$>\operatorname{Load} 1-1.2 \mathrm{~kW}$

$>\operatorname{Load} 2-1.8 \mathrm{~kW}$

$>\operatorname{Load} 3-1.3 \mathrm{~kW}$

- It is considered that all the three loads are smart appliances and has the ability to communicate and interact with the smart controller and each other though the HAN. 
- The smart controller stores the scheduled run time entered by the consumer after analyzing the electricity price signals sent by the utility over the AMI.

- The smart controller can also tell the consumer the best possible schedule run time for the loads to save on the electricity bills on the consumer side as well as to reduce the PD on the grid.

- It is assumed that the utility and the grid operators are using the ToUT method for demand side management

- Weekday electricity prices are considered, as it is more complex to manage the loads during the weekdays.

- Each case has certain assumptions, which are highlighted wherever needed.

\subsubsection{Optimization formulation and algorithm}

\subsubsection{A) Intervals throughout the day}

This section defines the intervals in a day. A day consists of 24 hours so a single day is divided into 24 intervals. It is assumed that the first interval starts from 12:00am as the day begins from 12:00 am and finishes at 1:00 am and similarly the second interval would start from 1:00 am to 2:00am and so on till the last interval i.e. 11:00 pm to 12:00 am. The letter ' $t$ ' denotes the $t^{t h}$ interval, for example if $t=3$ that means it is the third interval, where $1 \leq t \leq 24$. The figure below shows how the day is spilt into 24 intervals.

\begin{tabular}{|l|l|l|l|l|l|l|l|l|l|l|}
\hline 1 & 2 & 3 & 4 & $\ldots$ & 19 & 20 & 21 & 22 & 23 & 24 \\
\hline 0 & 1 & 2 & $\ldots$ & \multicolumn{10}{|c|}{} \\
\hline
\end{tabular}

Figure 10 - 24 intervals representing 24 hours in a day

The details of the time intervals assumed in this formulation are below. 


\begin{tabular}{|c|c|c|}
\hline Period & Time & Electricity Price \\
\hline OFF - Peak & $12 \mathrm{am}-8 \mathrm{am}, 7 \mathrm{pm}-12 \mathrm{am}$ & 7 cents $/ \mathrm{kWh}$ \\
\hline ON - Peak & $12 \mathrm{pm}-7 \mathrm{pm}$ & 14 cents $/ \mathrm{kWh}$ \\
\hline MID - Peak & $8 \mathrm{am}-12 \mathrm{pm}$ & 10 cents $/ \mathrm{kWh}$ \\
\hline
\end{tabular}

Table 1 - Electricity pricing for different periods throughout the day

\subsubsection{B) Load function}

Every single load in a smart home is defined by four parameters that are -

I. $\mathrm{Li}_{\mathrm{i}}$ - Lower limit of the interval

II. $\mathrm{U}_{\mathrm{i}}$ - Upper limit of the interval

III. $Z_{i}-$ Total duration for which the load remain in the running state (ON state)

IV. $\mathrm{Ri}_{\mathrm{i}}$ - Power rating of the load in $\mathrm{kW}$

Hence the load function can be defined as $F_{i}=\left(\mathrm{Li}_{\mathrm{i}}, \mathrm{U}_{\mathrm{i}}, \mathrm{Z}_{\mathrm{i}}, \mathrm{R}_{\mathrm{i}}\right)$ where ' $\mathrm{i}$ ' denotes the load.

For example if $F_{i}=[3,11,2,9]$, means that the load $\boldsymbol{i}$, which has a rating of $9 \mathrm{~kW}$ can be turned on anywhere between the $3^{\text {rd }}$ and the $11^{\text {th }}$ interval. Once it is turned ON it will stay in ON state for next 2 intervals.

\subsubsection{C) Load Scheduling}

- Let $k_{i}^{t}$ denotes the status of the $i^{\text {th }}$ load during the $t^{\text {th }}$ interval.

- If $k_{i}^{t}=1$ means that the $i^{t h}$ load is ON during the $t^{t h}$ interval and when $k_{i}^{t}=0$ means it is $\mathrm{OFF}$.

- The scheduling problem is to find the sequence of the decisions made by the consumer such that the total cost of the electricity consumed for the day is minimized.

$$
\mathrm{K}=k_{1}^{1}, k_{1}^{2}, \ldots, k ; k_{2}^{1}, k_{2}^{2}, \ldots, k_{2}^{24} ; \ldots ; k_{m}^{1}, \ldots \ldots, k_{m}^{24}
$$

- Let $C^{k}$ be the cost of one $\mathrm{kWh}$ of energy during the $t^{\text {th }}$ time interval and $\mathrm{Ri}_{\mathrm{i}}$ is the power rating of the load in $\mathrm{kW}$. Then the load scheduling problem can be stated as- 


$$
\min \sum_{t=1}^{24} \sum_{i=1}^{m} C^{k} \mathrm{R}_{\mathrm{i}} k_{i}^{t}
$$

such that,

$$
\begin{array}{ll}
\sum_{t=L_{i}}^{U_{i}} k_{i}^{t}=Z_{i} & \\
k_{i}^{t}=0 & \mathrm{Li}_{\mathrm{i}}>\mathrm{t}>\mathrm{U}_{\mathrm{i}}
\end{array}
$$

Where $\mathrm{t}=1,2, \ldots \ldots, 24$ and $\mathrm{i}=1,2, \ldots, \mathrm{m}$

Hence the main aim here is to optimized the above equation by making it minimum that consists of the cost of energy for the whole day, the power rating of the load and the status of the load. The flow chart below gives a brief idea of the process.

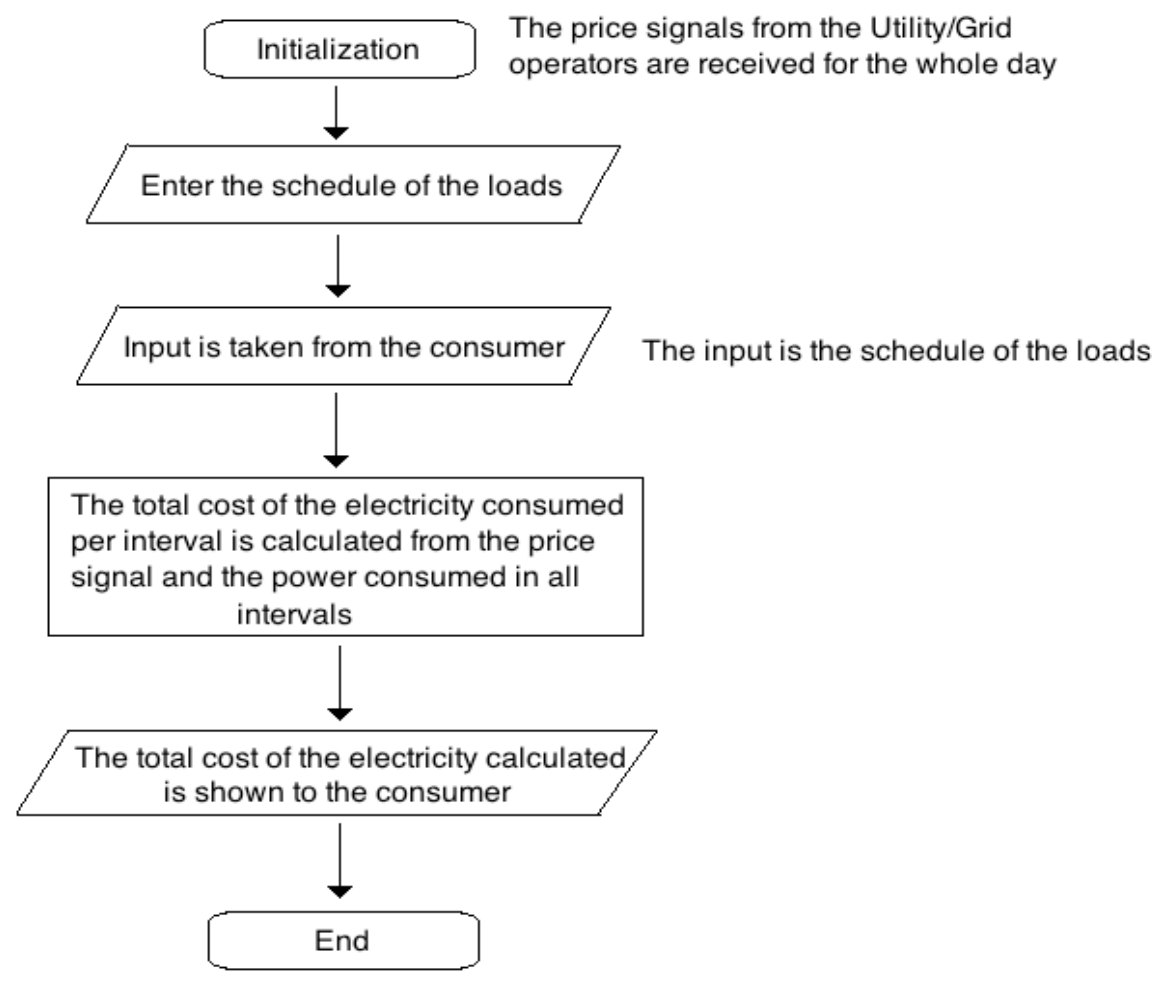

Figure 11 - Flowchart explaining the brief process of DSM 
But if all the consumers receive the same price signals, the entire consumer community will schedule the loads by shifting demand to the hours with lower price, which would lead to a new peak load and higher peak-to-average ratio at lower price times. The graphs below illustrate the same.

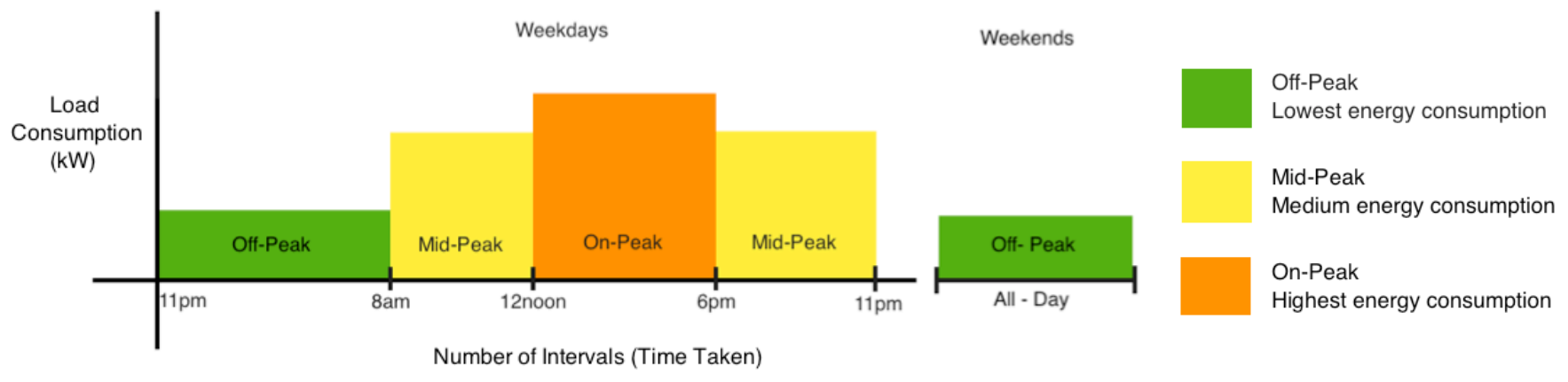

Figure 12 - Traditional load profile (non-optimized)

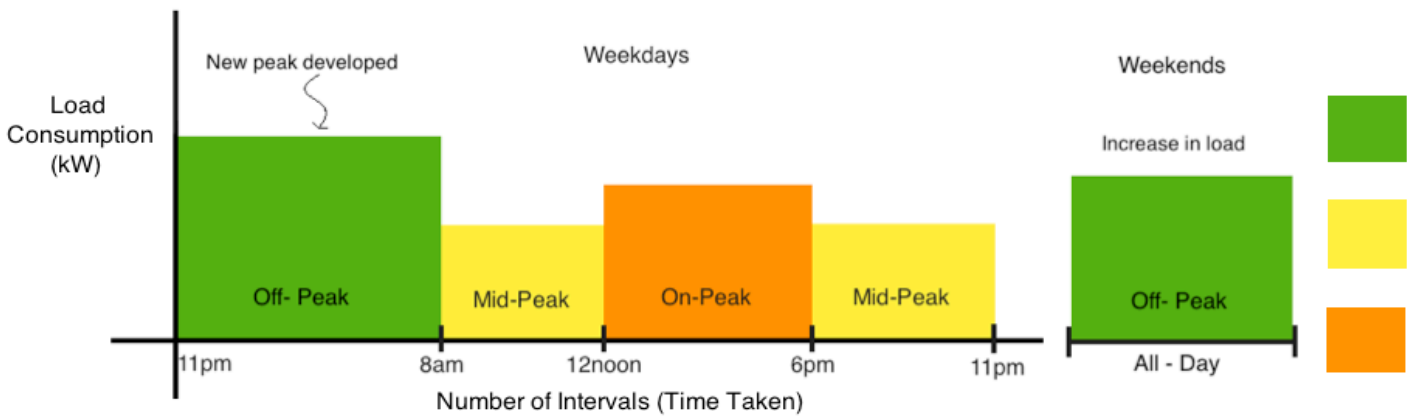

Off-Peak

Lowest energy consumption

Mid-Peak

Medium energy consumption

On-Peak

Highest energy consumption

Figure 13 - Optimized load profile through DSM

As we see from the graphs above the formulation does reduce the electricity demand a new peak demand is generated on the grid as majority of the consumers shifted their loads to offpeak periods i.e. lower price intervals. Few cases are presented below which optimizes the distribution of the loads by providing certain constraints.

\subsubsection{Optimizing the second peak demand generated on the grid}

\subsubsection{1) Case 1}

In this case the consumer can set up a constraint in the smart controller to limit his/her electricity bill for the day or month. This option is very useful for the consumer as it helps to keep the consumer informed of the total consumption. 
- For e.g. - If the limit set by the consumer is $\$ 100$ for a month then if the total cost of the electricity for the month goes beyond $\$ 100$ the consumer will be prompted about the limit violation and then to avoid increase in the cost of electricity the consumer can reschedule the loads.

- Assumption in this case - The parameter " $C_{l}$ " which is the cost limiting variable is set to $\$ 0.40$ per day. So if the cost of the electricity goes beyond this value then the consumer will be prompted regarding the constraint violation and further action can be taken by rescheduling the loads or the consumer can also go with the initial choice.

- So if every consumer were to set a cost constraint the load consumption per consumer itself shall get reduced.

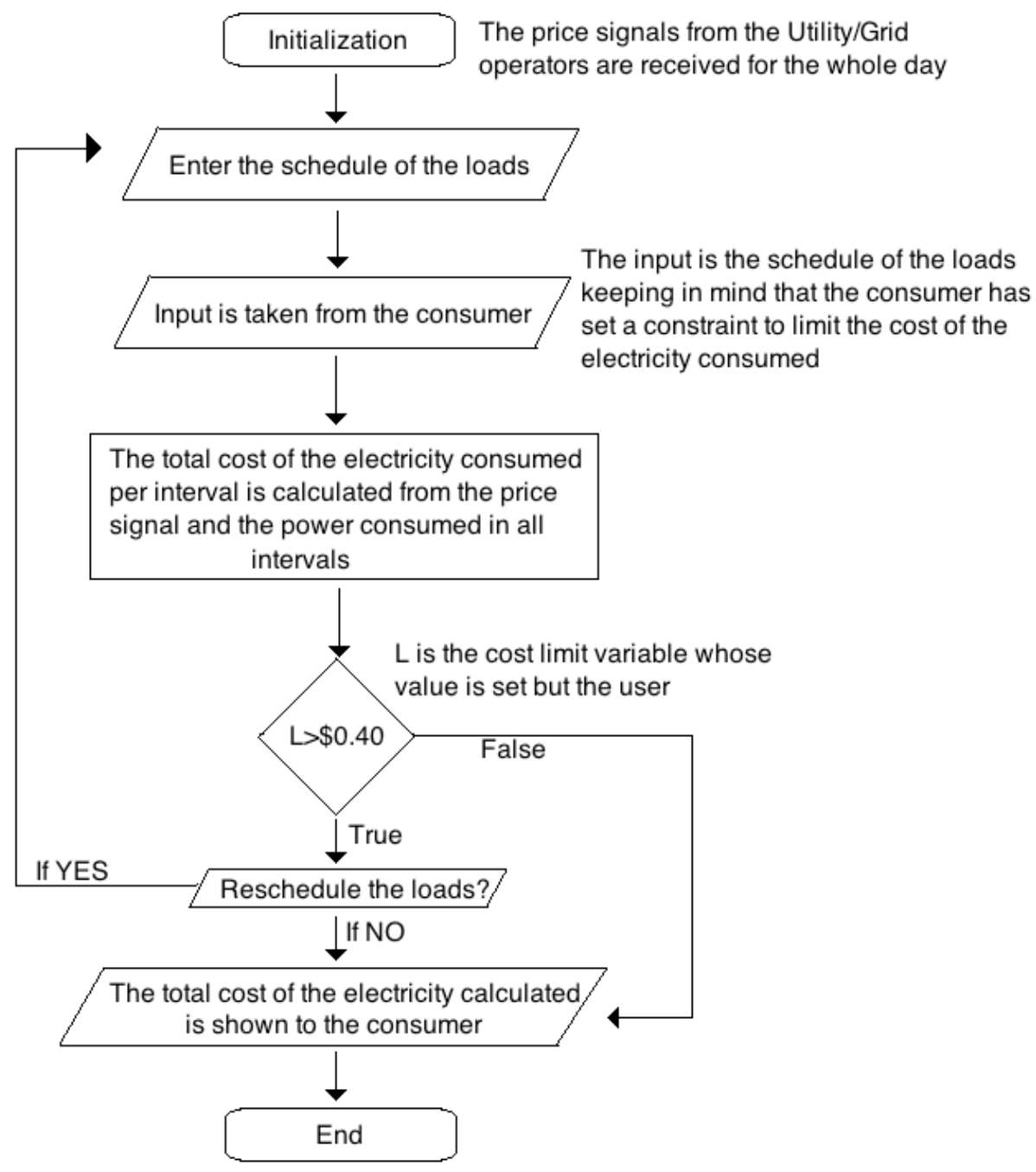

Figure 14 - Flow chart explaining the case 1 in part 1. Here the consumer sets a constraint 
The flowchart explains the cost constraint phenomena. Graphical comparison is done in the next chapter using simulation results.

\section{Advantages of Case 1}

- The consumer can save money on electricity bills, as the smart controller would prompt the consumer if he/she goes beyond a defined value.

- If most of the consumers were to set a proper cost constraint it will have an effect on reducing the $\mathrm{PD}$ as cost constraint is a function of load consumed by the end consumer.

\section{Disadvantages of Case 1}

- If none or very less amount of consumers participates by setting a constraint then the outcome (second peak generated) would remain nearly same.

\subsubsection{2) Case 2}

- In this case the utility can set a certain limit on the consumption of the electricity in a particular interval to avoid the second peak on the grid.

- So if the consumer violates the constraints set by the utility he/she will be penalized and charged extra for the over usage.

- Assumption made in this case - The limit " $H$ " set by the utility is 2 kilowatt for a particular interval i.e. if the consumer schedules the load in a way where the total consumption of electricity goes beyond the constraint $(2 \mathrm{~kW})$ set by the utility, then the consumer will be prompted regarding the constraint violation and the consumer will be given a chance to reschedule the loads, if not then a penalty factor shall be added in the total cost of the electricity bill.

- The penalty factor " $\mathrm{B}$ " $=1.5$ 


\section{Advantages of Case 2}

- The utility has a direct command on the demand. It can set constraints to keep the PD low on the grid as well as try to keep the consumers at comfort.

\section{Disadvantages of Case 2}

- If the consumer needs to consume more energy then the constraint set by utility then he/she will have to pay a penalty for violating the constraint.

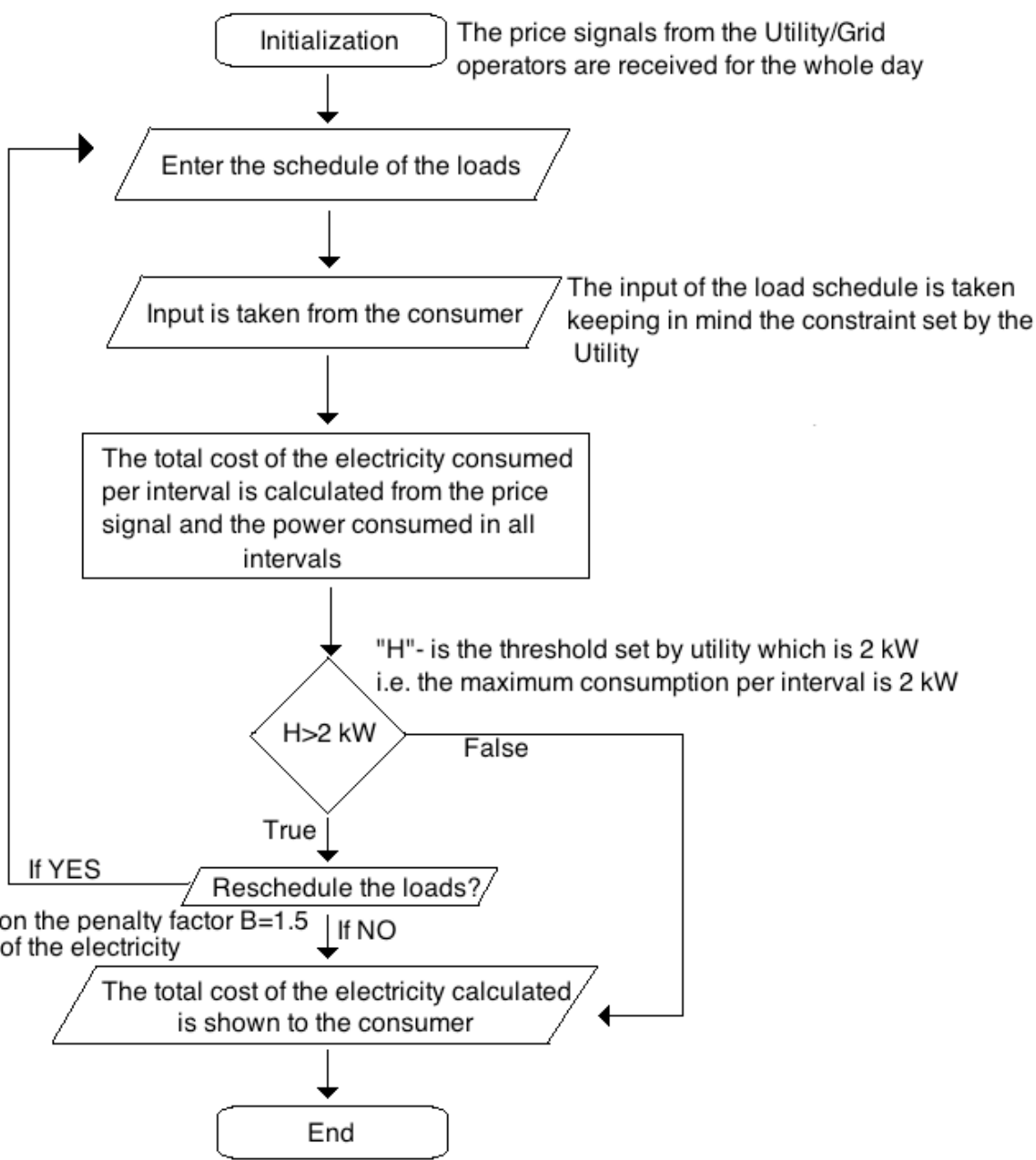

Figure 15 - Flowchart explaining case 2 in part 1 where utility sets the constraint 


\subsubsection{3) Case 3}

- This is a hybrid case where both the utility and the consumer sets the constraints

- The utility sets a limit on consumption in a particular interval. Hence "H" $=2 \mathrm{~kW}$.

- The consumer has set a limit of $\$ 0.40$ per day cost of the total electricity consumed. Hence "L" $=\$ 0.40$.

- The penalty factor " $\mathrm{B}$ " $=1.5$ is multiplied to the total cost if the constraints set by utility is violated.

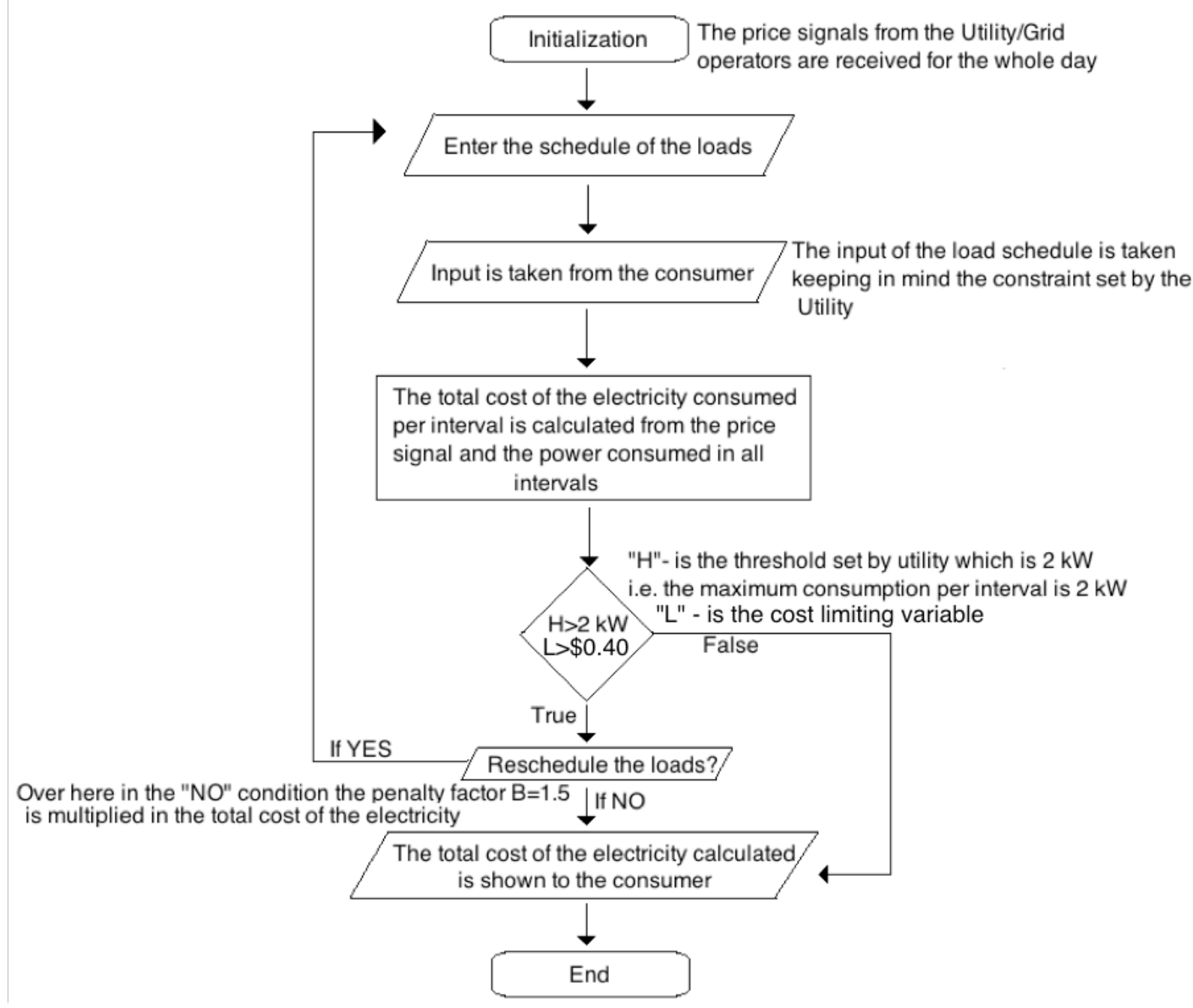

Figure 16 - Flowchart explaining the case 3 in part 1. This is a hybrid case where the utility ad consumer both can set up a constraint 
So from these cases we can understand that the optimization done to avoid the second peak generated is effective and beneficial for both the consumer and the utility also it improves the reliability of the grid.

However the non-schedulable loads are still running during the peak demand period contributing to the PD on the grid. This approach cannot manage such loads. The next part explains how the temperature dependent loads can be managed and eventually reduces the peak on the grid.

\subsection{Part 2: Non-schedulable loads}

Loads such as HVAC system and refrigeration are temperature dependent loads. It is not possible to schedule such loads as they operate throughout the day depending on the temperature of the house and the device. For instant when people or consumers wake up they will increase the temperature of their HVAC system to warm up the house. In this part HVAC system is considered and to optimize the operation of the system to reduce the PD on the grid the run time is expanded to distribute the load consumption over a larger time frame. So if the consumer wants to have a specific temperature by morning say 6:00am when he/she wakes up then the HVAC will run a bit before 6:00am and attain the desired temperature by the time consumer wakes up.

\subsubsection{Assumptions and General Explanation}

- A community of 20 houses is considered in this part, where each house has a HVAC system. The aim is to optimize the load consumption by distributing it over time.

- Each house is considered as a smart home with the ability to effectively communicate with all the appliances that are connected to the smart controller through HAN and the smart controller is connected to the utility through the AMI so that the arrangement can have two-way interaction. 
- It is assumed that the only source of Heat Gain is through HVAC system.

- All the 20 houses are grouped into four groups with each group having five houses.

- The criterion to group these houses is usually based on the temperature reading of each house.

- It is assumed that the time needed by the HVAC system to raise the temperature of a house is 5 minutes. Also in addition to this each case presented below has their assumption.

- The consumer in each house shall enter his/her desired temperature for the next morning into the smart controller before going to sleep. Let this desired temperature be "D" in ${ }^{\circ} \mathrm{C}$.

- The smart controller will also record the thermostat temperature or the home's temperature the next day in the morning before the formulation begins. This temperature is known as " $\mathrm{T}$ " in ${ }^{\circ} \mathrm{C}$.

$>$ For e.g. if the desired temperature entered by the consumer is $22^{\circ} \mathrm{C}$ and the thermostat reading is $18^{\circ} \mathrm{C}$. Then,

$$
\begin{aligned}
\mathrm{D}-\mathrm{T} & =22^{\circ} \mathrm{C}-18^{\circ} \mathrm{C} \\
& =4^{\circ} \mathrm{C}
\end{aligned}
$$

As shown in the above point that time taken by the HVAC system to raise the temperature of the house by $1^{\circ} \mathrm{C}$ is 5 minutes then for this house having $4^{\circ} \mathrm{C}$ difference, the HVAC system will have to run for $5 \times 4=20$ minutes to attain the desired temperature. 
- The following equation gives amount of run time of the HVAC system, which is denoted by ' $N$ '. N/4 (as we have 4 groups we divide the time by 4 ) minutes will be required to attain the desired temperature. When multiplied by 5 it will give the amount of time needed to run the HVAC system to attain the desired temperature.

$$
\mathrm{N}=\left(\sum_{k=1}^{20} D_{k}-T_{k}\right) * 5
$$

Where $k=k^{t h}$ house.

- To find the total run time of the whole (20 houses) system, the value $\mathrm{N}$ is divided by 4 as there are four groups. Hence the utility or the HVAC system should at least begin the operation by $\mathrm{N} / 4$ minutes before the consumer wakes up.

- The difference of the desired temperature and the thermostat temperature will give the HVAC run time for that house.

- The smart controller will collect the desired temperatures from all the 20 houses and will send it to the utility or the central data management system (CDMS).

- It is assumed that all the consumers in these 20 houses will wake up at 6:30 am so by this time the HVAC should attain the desired temperature of each house.

- The utility/CDMS will receive the data and prepare the algorithm for the HVAC run time in all houses for the next day.

- It is made sure that no two groups are $\mathrm{ON}$ at the same time. At a give instant of time only one group will operate and eventually turn the HVAC system ON for all houses in that group. 
- The houses are sorted and grouped in the ascending order of their thermostat temperature readings with group 1 having houses with lowest thermostat reading to group 4 consisting of houses with highest thermostat reading.

\subsubsection{HVAC operating sequence}

As we know that the thermostat temperature reading for all the 20 houses is $T_{1}, T_{2}, T_{3}, \ldots \ldots, T_{20}$ and the desired temperature entered by the consumer is assumed to be $21^{\circ} \mathrm{C}$. Therefore $D_{1}, D_{2}$, $D_{3}, \ldots \ldots, D_{20}=21^{\circ} \mathrm{C}$.

Let us consider that the thermostat readings (in ${ }^{\circ} \mathrm{C}$ ) recorded by the smart controller of each house is

\begin{tabular}{|l|l|l|l|l|l|l|l|l|l|l|l|l|l|l|l|l|l|l|l|}
\hline$T_{1}$ & $T_{2}$ & $T_{3}$ & $T_{4}$ & $T_{5}$ & $T_{6}$ & $T_{7}$ & $T_{8}$ & $T_{9}$ & $T_{10}$ & $T_{11}$ & $T_{12}$ & $T_{13}$ & $T_{14}$ & $T_{15}$ & $T_{16}$ & $T_{17}$ & $T_{18}$ & $T_{19}$ & $T_{20}$ \\
\hline 16 & 18 & 17 & 19 & 20 & 17 & 18 & 17 & 20 & 19 & 16 & 18 & 17 & 19 & 20 & 17 & 18 & 17 & 20 & 19 \\
\hline
\end{tabular}

The houses are first sorted with ascending thermostat temperature readings and then grouped into four groups.

\begin{tabular}{|l|l|l|l|l|l|l|l|l|l|l|l|l|l|l|l|l|l|l|l|}
\hline$T_{1}$ & $T_{11}$ & $T_{3}$ & $T_{6}$ & $T_{8}$ & $T_{13}$ & $T_{16}$ & $T_{18}$ & $T_{2}$ & $T_{7}$ & $T_{12}$ & $T_{17}$ & $T_{4}$ & $T_{10}$ & $T_{14}$ & $T_{20}$ & $T_{5}$ & $T_{9}$ & $T_{15}$ & $T_{19}$ \\
\hline 16 & 16 & 17 & 17 & 17 & 17 & 17 & 17 & 18 & 18 & 18 & 18 & 19 & 19 & 19 & 19 & 20 & 20 & 20 & 20 \\
\hline
\end{tabular}

As shown above in the table

Group $1-T_{1}, T_{11}, T_{3}, T_{6}, T_{8}$

Group 2 - $T_{13}, T_{16}, T_{18}, T_{2}, T_{7}$

Group 3 - $T_{12}, T_{17}, T_{4}, T_{10}, T_{14}$

Group 4 - $T_{20}, T_{5}, T_{9}, T_{15}, T_{19}$

Now the next step is to find out the overall amount of run time for the HVAC system in all houses. The difference between the thermostat temperature and desired temperature multiplied by the amount of time taken by the HVAC system to raise the temperature of the house by $1^{\circ} \mathrm{C}$ 
which is 5 minutes here, will give the total run time. Consider the below equation for this calculation.

$$
\mathrm{N}=\left(\sum_{k=1}^{20} D_{k}-T_{k}\right) * 5
$$

Where, $\quad D_{k}=21^{\circ} \mathrm{C}$ for all the houses

$\mathrm{N} / 4$ = Total run time of the HVAC system for all the groups

$T_{k}=$ Thermostat temperature reading for the $k^{\text {th }}$ house

The HVAC system in Group 1 is turned ON first at least N/4 minutes before the consumer wakes up till the temperature of all 5 houses is raised by $1^{\circ} \mathrm{C}$ which takes 5 minutes as we can see from the table number this group consists of houses with least thermostat readings. After every interval i.e. after every 5 minutes of operation the thermostat temperature readings of each group are compared and hence the group having near lowest thermostat temperature reading will turn their HVAC system next. The sequence in this case is shown below.

\begin{tabular}{|c|c|c|c|c|c|c|}
\hline \multirow{2}{*}{$\begin{array}{c}\text { Interval } \\
\\
1\end{array}$} & \multirow{2}{*}{$\begin{array}{c}\text { Group } \\
1\end{array}$} & \multicolumn{5}{|c|}{$\begin{array}{c}\text { Temperature of the houses in }{ }^{\circ} \mathrm{C} \text { after } \\
\text { each interval }\end{array}$} \\
\hline & & 17 & 17 & 18 & 18 & 18 \\
\hline 2 & 2 & 18 & 18 & 18 & 19 & 19 \\
\hline 3 & 1 & 18 & 18 & 19 & 19 & 19 \\
\hline 4 & 3 & 19 & 19 & 20 & 20 & 20 \\
\hline 5 & 2 & 19 & 19 & 19 & 20 & 20 \\
\hline 6 & 1 & 18 & 18 & 19 & 19 & 19 \\
\hline 7 & 4 & 20 & 21 & 21 & 21 & 21 \\
\hline 8 & 3 & 20 & 20 & 21 & 21 & 21 \\
\hline 9 & 2 & 19 & 19 & 19 & 20 & 20 \\
\hline 10 & 1 & 18 & 18 & 19 & 19 & 19 \\
\hline 11 & 4 & 21 & - & - & - & - \\
\hline 12 & 3 & 21 & 21 & - & - & - \\
\hline 13 & 2 & 21 & 21 & 21 & - & - \\
\hline 14 & 1 & 21 & 21 & - & - & - \\
\hline
\end{tabular}

Table 2 - HVAC operation sequence for all 20 houses 
The total amount of time needed for complete HVAC operation in all 20 houses to attain the desired temperature is $\mathrm{N} / 4=70$ minutes. So the utility/CDMS should al least begin the sequence 70 minutes before the consumer wakes up.

\subsubsection{1) Case 1}

- In this case the power rating of all the HVAC system is considered the same and the rating is $4.5 \mathrm{~kW}$.

- It is assumed that there is no heat loss in the house hence the temperature attained will remain the same.

\subsubsection{2) Case 2}

- In this case different house sizes and corresponding to that size different capacity/power rating of the HVAC system is considered.

- The houses considered are small (S), medium (M) and large (L) with HVAC power rating of $3.5 \mathrm{~kW}, 4.5 \mathrm{~kW}$ and $5.5 \mathrm{~kW}$ respectively.

- It is assumed that there is no heat loss in the house hence the temperature attained will remain the same.

- All the 20 houses are randomly allotted different sizes as shown below.

- The table below shows random allocation of different sizes to all the houses. 


\begin{tabular}{|c|c|c|c|}
\hline House & Temperature & Size & $\mathrm{kW}$ rating \\
\hline 1 & 16 & $\mathrm{~S}$ & 3.5 \\
\hline 2 & 18 & $\mathrm{M}$ & 4.5 \\
\hline 3 & 17 & $\mathrm{~L}$ & 5.5 \\
\hline 4 & 19 & $\mathrm{~S}$ & 3.5 \\
\hline 5 & 20 & M & 4.5 \\
\hline 6 & 17 & $\mathrm{~L}$ & 5.5 \\
\hline 7 & 18 & $\mathrm{~S}$ & 3.5 \\
\hline 8 & 17 & $\mathrm{M}$ & 4.5 \\
\hline 9 & 20 & $\mathrm{~L}$ & 5.5 \\
\hline 10 & 19 & $\mathrm{~S}$ & 3.5 \\
\hline 11 & 16 & M & 4.5 \\
\hline 12 & 18 & $\mathrm{~L}$ & 5.5 \\
\hline 13 & 17 & $S$ & 3.5 \\
\hline 14 & 19 & $\mathrm{M}$ & 4.5 \\
\hline 15 & 20 & $\mathrm{~L}$ & 5.5 \\
\hline 16 & 17 & $\mathrm{~S}$ & 3.5 \\
\hline 17 & 18 & $\mathrm{M}$ & 4.5 \\
\hline 18 & 17 & $\mathrm{~L}$ & 5.5 \\
\hline 19 & 20 & $S$ & 3.5 \\
\hline 20 & 19 & M & 4.5 \\
\hline
\end{tabular}

Table 3 - Random allocation of size of the house which are small(S), medium $(M)$, and large $(L)$

- After sorting all the houses with ascending thermostat temperature readings and grouping them into four groups it looks same as below. 


\begin{tabular}{cccccccc}
\hline & \multicolumn{2}{c}{ Group 1 } & \multicolumn{5}{c}{ Group 2 } \\
\hline House & Temperature & Size & Rating & House & Temperature & Size & Ratin \\
& & & & & & & $\mathrm{g}$ \\
1 & 16 & $\mathrm{~S}$ & 3.5 & 13 & 17 & $\mathrm{~S}$ & 3.5 \\
11 & 16 & $\mathrm{M}$ & 4.5 & 16 & 17 & $\mathrm{~S}$ & 3.5 \\
\hline 3 & 17 & $\mathrm{~L}$ & 5.5 & 18 & 17 & $\mathrm{~L}$ & 5.5 \\
6 & 17 & $\mathrm{~L}$ & 5.5 & 2 & 18 & $\mathrm{M}$ & 4.5 \\
8 & 17 & $\mathrm{M}$ & 4.5 & 7 & 18 & $\mathrm{~S}$ & 3.5 \\
\hline
\end{tabular}

\begin{tabular}{cccccccc}
\hline & \multicolumn{2}{c}{ Group 3 } & \multicolumn{5}{c}{ Group 4 } \\
\hline House & Temperature & Size & Rating & House & Temperature & Size & Rating \\
12 & 18 & L & 5.5 & 20 & 19 & M & 4.5 \\
17 & 18 & M & 4.5 & 5 & 20 & M & 4.5 \\
4 & 19 & S & 3.5 & 9 & 20 & L & 5.5 \\
10 & 19 & S & 3.5 & 15 & 20 & L & 5.5 \\
14 & 19 & M & 4.5 & 19 & 20 & S & 3.5 \\
\hline
\end{tabular}

\subsubsection{3) Case 3}

In this case heat loss factor in each house is considered. Also more energy might be utilized in total as to compensate the heat loss the HVAC system is turned ON. The added load in total is not considered in the comparison, as the main aim is to reduce the Peak Demand generated. Hence it is assumed that the total load consumption in optimized and traditional approach is the same. Let us understand the phenomena first.

\section{What is heat loss?}

A consumer prefers to have inside temperature of the house to be around $20^{\circ} \mathrm{C}$ during the 
winters. However, as the temperature is lower outside, the heat from the house travels through the house envelope, the walls, windows and ceilings to the outside. This heat from the house is lost by conduction. Furthermore, as there a temperature difference cold winter air leaks into the house and warm air leaks out. This is known as infiltration.

There is a constant movement of heat from the inside of the house to the outside, which is measured in units known as BTUs (British Thermal Units). The speed at which the heat travels outside is called the Heat Loss and is measured in BTUH, i.e. BTUs per hour.

If the temperature is around $21^{\circ} \mathrm{C}$ inside the house and $10^{\circ} \mathrm{C}$ outside, then the $11^{\circ} \mathrm{C}$ temperature difference will cause a certain number of BTUs or heat to leave the house every hour, let's say that, that value is ' $x$ ' BTUH. The heat loss of this house at $10^{\circ} \mathrm{C}$ is ' $x$ ' BTUH. This means that your heating system needs to produce ' $x$ ' BTUs each hour to keep the inside temperature of the house at $21^{\circ} \mathrm{C}$ when the outside temperature is $10^{\circ} \mathrm{C}$.

The house will lose more heat every hour and will have higher heat loss, if it is even colder outside. So the Heat Loss of the house is defined as the number of BTUs lost every hour

Here is a summary of the factors affecting heat loss

1. Temperature difference - Reducing the inside temperature and moving to a warmer climate are two ways to reduce heat loss

2. Area of the building envelope - Smaller houses have lower heat losses than larger ones.

3. Thermal Resistance - Adding insulation to the walls and ceiling (increasing R-value) slows the movement of heat, thus reducing heat loss.

4. Tightness - Better window frames, sealing cracks reduces infiltration. 


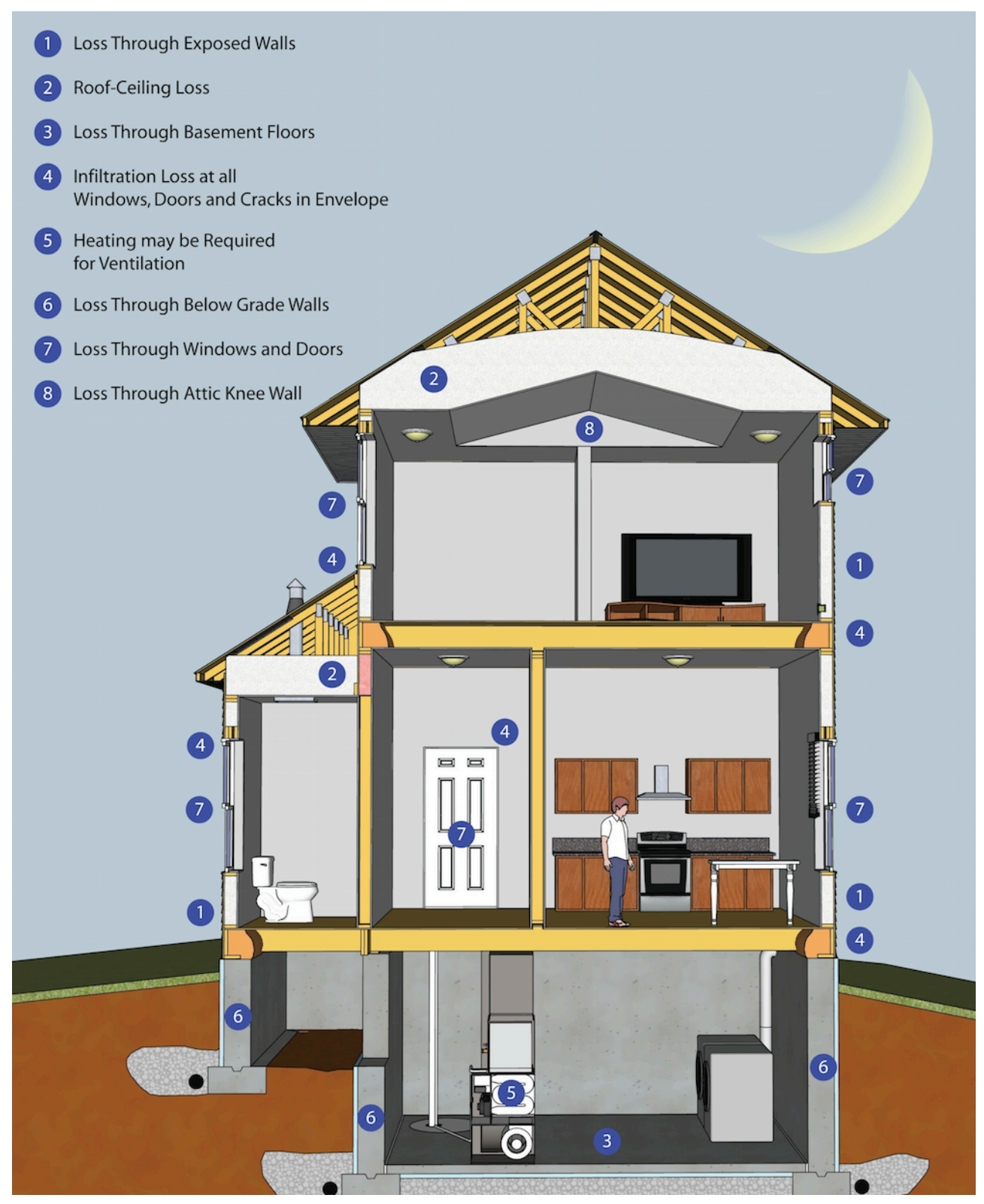

Figure 17 - Schematic of a house showing possible area for heat loss [38]

\section{Calculations}

Let the total heat loss be denoted by ' $Q$ ' hence the heat loss is computed as follows -

$$
\mathrm{Q}=\frac{\mathrm{A} * \Delta T}{\mathrm{R}} \quad \mathrm{BTU} / \mathrm{hr}
$$


Where,

'A' - the total area of the house that separates the heating area of the house with the outside

' $\Delta T$ ' - Difference between inside and outside temperature

' $R$ ' - Resistance of the surface to the transfer of heat

Larger the value of ' $A$ ' means the area through which the heat can be lost is large and more heat is required to be generated to compensate the loss, hence the capacity of HVAC increases with the increase in overall area of the house.

If the temperature difference between the outside and inside temperature is high then the speed at which the heat transfer occurs is higher as more pressure is developed with increase in the temperature difference $(\Delta T)$.

The R-value is the thermal resistance of the surface and hence the heat loss reduces if the value of $\mathrm{R}$ is high.

Overall considering the heat loss in the optimization formulation changes the value of $\mathrm{N}$ i.e. the total run-time of the HVAC system in each house, as the HVAC has to compensate the heat loss.

We consider that the heat loss in the small house is less than the medium house and the large house has the highest heat loss. As all the 20 houses are a community we assume that some houses are new with new insulation i.e. higher value of ' $R$ ' and some are old with old insulation i.e. lower value of ' $\mathrm{R}$ '. The difference between outside and inside temperature ' $\Delta T$ ' is considered same for all the houses.

So considering different values of ' $A$ ' and ' $R$ ' it takes about 15 minutes for a large house to lose heat to decrease the temperature of the house by $1^{\circ} \mathrm{C}$. Similarly for medium house it takes about 20 minutes and for small house it takes about 25 minutes.

The power rating of the large, medium and small houses are considered the same i.e. $5.5 \mathrm{~kW}$, $4.5 \mathrm{~kW}$ and $3.5 \mathrm{~kW}$ respectively. 
The houses are sorted and grouped the same way as that in case 2. But as we are considering the heat loss and different insulation level in all the houses we assume that to compensate for the heat loss in each house a portion of the HVAC system stays on to heat the house and balance the temperature.

For the small houses it takes about 25 minutes to lose the temperature of the house by $1^{\circ} \mathrm{C}$ due to heat loss. So to compensate for the heat loss and to keep the temperature of the house at constant level the HVAC in small houses will turn ON at $20 \%$ capacity. Similarly for medium houses the HVAC will turn ON at $25 \%$ capacity and for large houses the HVAC turn ON at $30 \%$ only a particular group stays off for more than two intervals. We assume that major heat loss occurs in the later portion of the time i.e. for large house major heat loss occurs in the last 5 minutes and so on for other two houses.

The rest part of the algorithm i.e. the HVAC run-time sequence remains the same as in case 2. Comparison is done in the simulation part between the traditional way of HVAC run-time and optimized approached and results show that implementing optimization algorithm reduces the PD.

The simulation results explain and supports the proposed technique well. The maintain aim is to reduce or flatten the peak generated by the HVAC system as shown in the figure below.

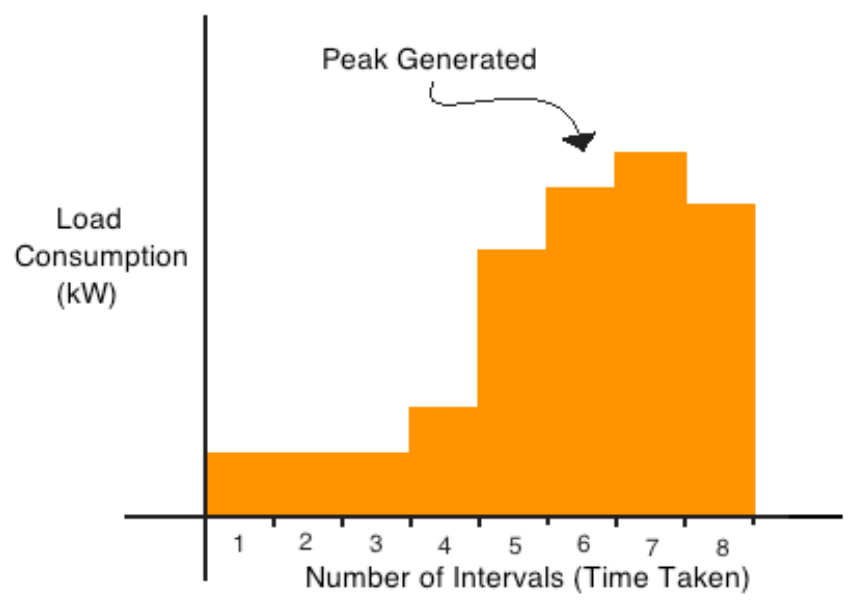

Figure 18 - Traditional non-optimized HVAC run time load profile with base load 
In fig. 14 the load profile shown is a traditional one where most of the consumer wakes up around the same time and then they turn the HVAC system ON to increase the temperature of the house. As most of the consumers turn the HVAC load ON at or around same time it contributes to peak demand on the grid during the morning times. The distributed load optimization method the whole peak generated by the HVAC system in morning can be well distributed and the PD can be reduced.

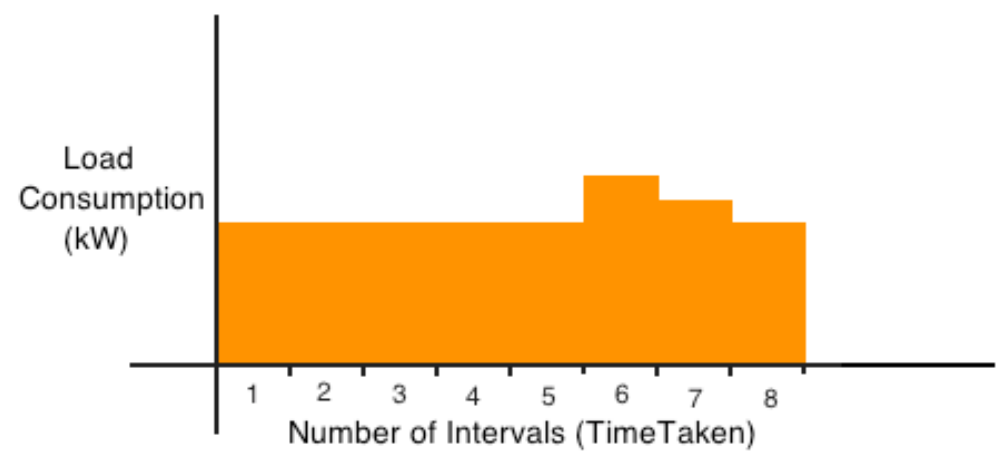

Figure 19 - Optimized load profile of the HVAC system where the load is distributed well over a lager timeframe

In fig. 15 the HVAC peak load is distributed using optimization algorithm discussed in this chapter where the HVAC are turned ON simultaneously few hours before the consumer wakes up. So by the time consumer wakes up he/she will have desired temperature inside the house. 


\section{Chapter - 5}

\section{SIMULATION AND RESULTS}

\subsection{Part 1 - schedulable loads}

\subsubsection{Case 1 - Consumer sets a cost constraint}

In this case the consumer itself sets a cost constraint the smart controller so whenever a consumer where to schedules more loads in peak period/high cost period the controller shall acknowledge the consumer that he/she is violating the cost constraint and will end up paying more money if the loads aren't rescheduled.

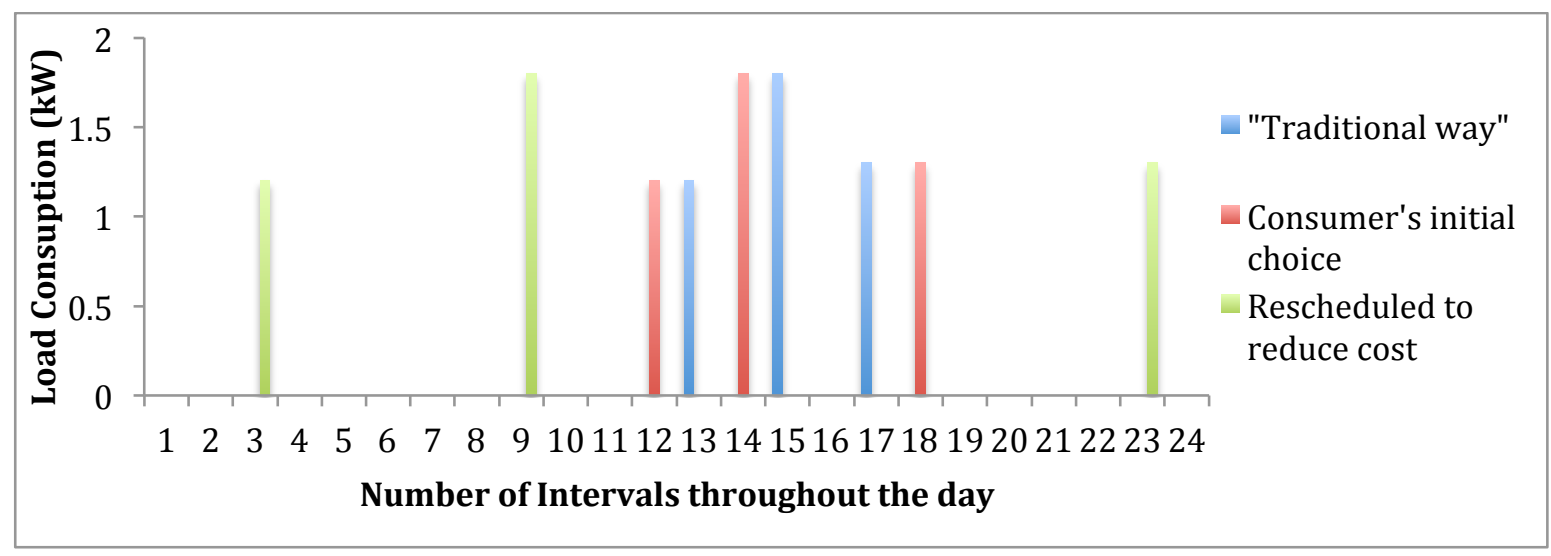

\section{Graph 1 - Case 1 of part 1 where consumer sets the constraint}

The traditional way (highlighted in color blue) shown in the graph above depicts the conventional run time of the loads where all the loads are scheduled in the on-peak period, which needs to be optimized to save money on bills and reduce the PD of the grid eventually.

The consumer's initial choice (highlighted in color red) depicts the initial preference of the consumer regardless of the constraints. The constraint set by the consumer helps him/her to save money on the monthly electricity bills. However this choice violates the cost constraint set by the consumer as shown in the simulation above. So, the smart controller prompts the 
consumer that he/she will violate the constraint if they go with the red choice. Hence they are given a chance to reschedule the loads.

If the consumer chooses to reschedule to save money then he/she can refer to the electricity price signal throughout day and find the best time to run their loads to save money. Finally the Rescheduled choice (highlighted in color green) done by the consumer will help him/her save money and eventually reduce the PD on the grid. The smart controller will store the rescheduled run time to operate the loads when the scheduled time arrives.

The main aim is to shift the loads from on-peak period to off-peak or mid-peak period and as we can see from the graph above that when the consumer is given the real time electricity price signals he/she can interact with the system through smart controller to manage their loads to shift it to lower price period. Hence save money as well as reduce the PD on the grid.

\subsubsection{Case 2 - Utility sets a constraint}

In this case the utility sets a consumption constraint of $2 \mathrm{~kW}$ in an interval. If the consumer violates this constraint by consuming electricity more than $2 \mathrm{~kW}$ then the consumer will be penalized and he/she will have to pay 1.5 times the actual electricity cost.

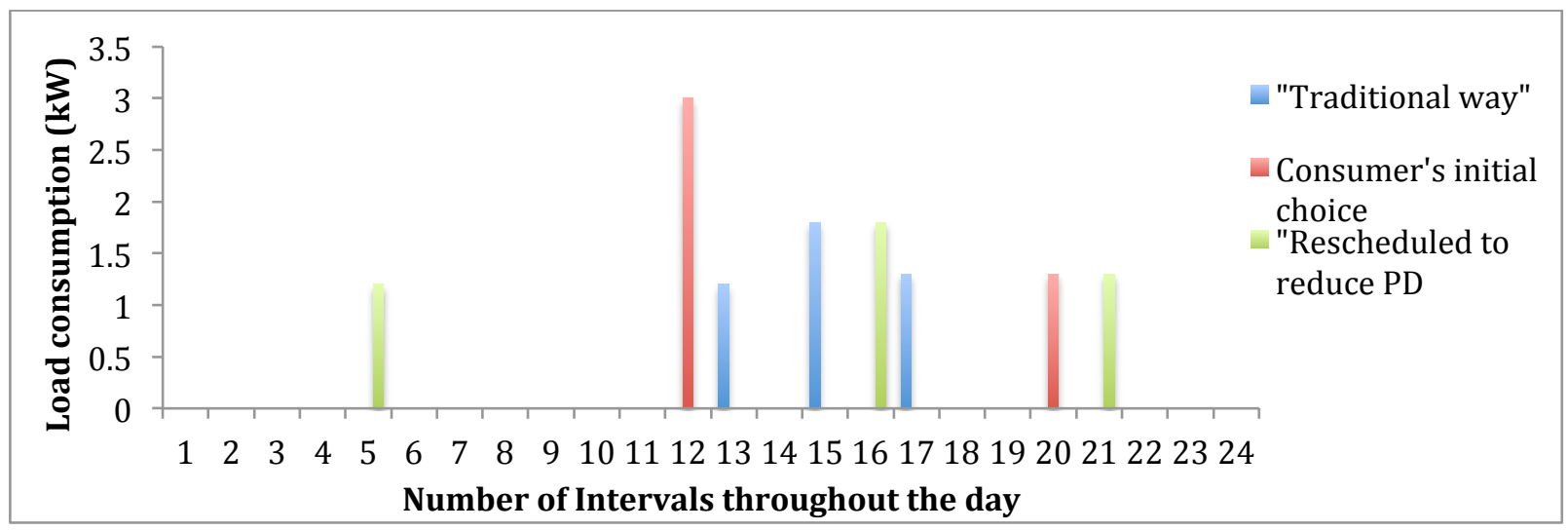

Graph 2 - Case 2 of part 1 where the utility sets the constraint 
The graphical notification is same as in graph no. 1. However here the utility wants to make sure that the consumers don't schedule their loads in the same interval, as it will increase the PD, so they set up a constraint of $2 \mathrm{~kW}$ usage in a particular interval. If the consumer violates the constraint he/she will be penalized for it and will have to pay 1.5 times the original price.

As we see that the consumer's initial choice of scheduling the loads is easily violating the constraints as the total consumption in on-peak period is more than $2 \mathrm{~kW}$. So the smart controller prompts the consumer that the have violated the constraint and if they still want to go ahead with this choice rather than rescheduling the loads they will have to pay a penalty factor of 1.5 .

The final rescheduled choice distributes the load well and consumption in each interval is less than $2 \mathrm{~kW}$. As the smart controller operates all the loads in the house the consumer can store the run time of the loads and with the advantage of automation the loads will run when the scheduled time arrives.

\subsubsection{Case 3 - Hybrid case where both the utility and consumer set a constraint}

One of the disadvantages of case 1 is only the consumer has command on managing the loads. Though it has a constraint of limiting the consumption through cost factor it can be still violated by the consumer by denying the rescheduling of the loads and if most of them were to do the same it will increase the PD on the grid. There is no penalty factor in this case even if the consumer violates the constraint. 


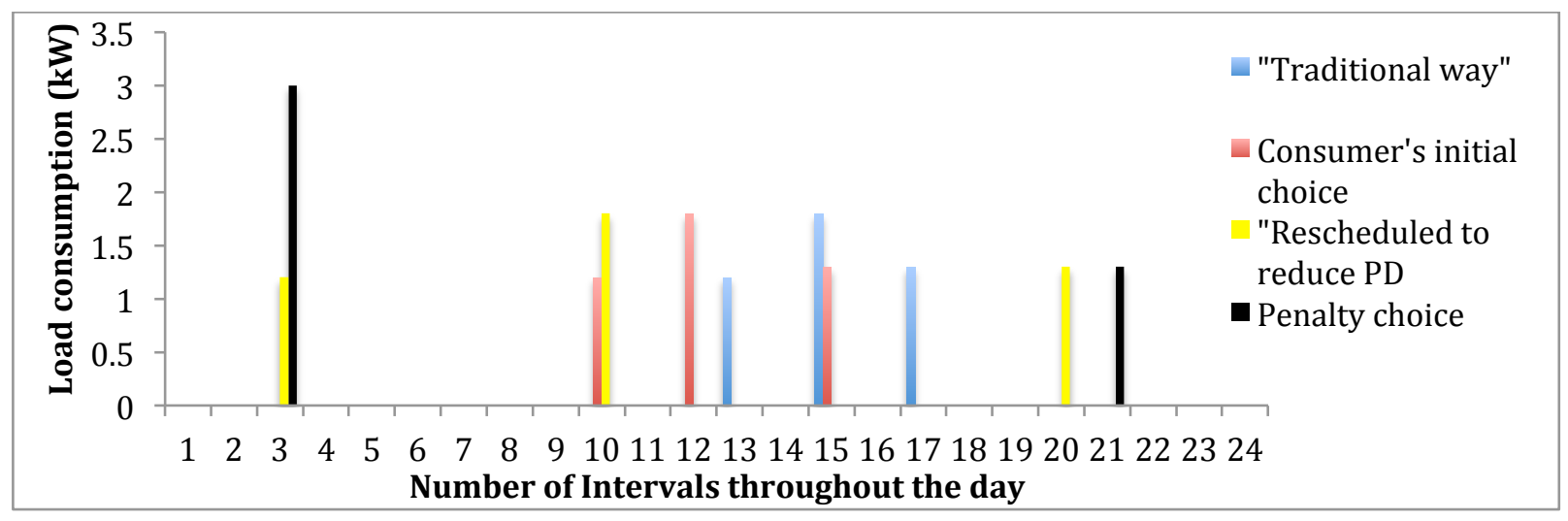

\section{Graph 3 - Case 3 of part 1. This is a hybrid case where both the consumer and utility set a constraint}

So to establish a better command on the grid and manage the loads more efficiently we designed case 2 where the utility sets a constraint to limit the consumption up to a certain limit for every period throughout the day. It is effective as there is a penalty charged to the consumers who violates the constraint.

However in case 3, which is the combination of case 1 and 2 both the consumer, and utility set a constraint and by this the consumer can save on bills and at the same time the utility can have a better command on the grid.

The traditional way (highlighted in color blue) shown in the graph above depicts the conventional run time of the loads that are operated during the on-peak period, which needs to be optimized to save money on bills and reduce the PD of the grid eventually.

The consumer's initial choice (highlighted in color red) depicts the initial preference of the consumer regardless of the constraints. The constraint set by the consumer helps him/her to save money on the monthly electricity bills. However this choice violates the cost constraint set by the consumer as shown in the simulation above. So, the smart controller prompts the consumer that he/she will violate the constraint if they go with the red choice. Hence they are given a chance to reschedule the loads. 
If the consumer chooses to schedule the penalty factor (highlighted in color black) shown in the graph he/she will be penalized by a factor of 1.5 times of the total consumption during that period because the consumer has violated the constraint by scheduling two loads in the same interval which mean the total consumption in that interval is more than $2 \mathrm{~kW}$.

If the consumer chooses to reschedule to save money then he/she can refer to the electricity price signal throughout day and find the best time to run their loads to save money. Finally the Rescheduled choice (highlighted in color yellow) done by the consumer will help him/her save money and eventually reduce the PD on the grid. The smart controller will store the rescheduled run time to operate the loads when the scheduled time arrives. 


\subsection{Part 2 - Non-schedulable loads (HVAC)}

In this Part the HVAC operating time is managed by utility. As explained in section 4.2 the load consumption of the HVAC in each house in the community is distribute over a larger timeframe. Assumptions have been stated in the same section.

\subsubsection{HVAC operating sequence Case 1}

\begin{tabular}{ccccc}
\hline \multicolumn{5}{c}{ Non - Optimized approach (original/traditional) } \\
\hline Interval & No of houses & Power rating & Time & Consumption \\
\hline $\mathbf{1}$ & 20 & (in $\mathrm{kW})$ & & (in $\mathrm{kW})$ \\
$\mathbf{2}$ & 16 & 4.5 & $6: 30$ & 90 \\
$\mathbf{3}$ & 12 & 4.5 & $6: 35$ & 72 \\
$\mathbf{4}$ & 8 & 4.5 & $6: 40$ & 54 \\
$\mathbf{5}$ & 2 & 4.5 & $6: 45$ & 36 \\
$\mathbf{6}$ & 0 & 4.5 & $6: 50$ & 9 \\
$\mathbf{7}$ & 0 & 4.5 & $6: 55$ & 0 \\
$\mathbf{8}$ & 0 & 4.5 & $7: 00$ & 0 \\
$\mathbf{9}$ & 0 & 4.5 & $7: 05$ & 0 \\
$\mathbf{1 0}$ & 0 & 4.5 & $7: 10$ & 0 \\
$\mathbf{1 1}$ & 0 & 4.5 & $7: 15$ & 0 \\
$\mathbf{1 2}$ & 0 & 4.5 & $7: 20$ & 0 \\
$\mathbf{1 3}$ & 0 & 4.5 & $7: 25$ & 0 \\
$\mathbf{1 4}$ & 0 & 4.5 & $7: 30$ & 0 \\
\hline
\end{tabular}

Table 4 - The table shows the HVAC operating sequence for non-optimized approach

- The table 4 above shows the operating sequence of the HVAC system in traditional way. Here the HVAC system in all the 20 houses is turned $\mathrm{ON}$ in the morning to raise the temperature of the house when the consumer wakes up i.e. at 6:30.

- Gradually as the intervals passes the load consumption reduces as the houses start attaining the desired temperature set by the consumer.

- It is noted that the total peak load is $90 \mathrm{~kW}$

- However in Table 5 below which shows the optimized operating sequence the HVAC starts operating $\mathrm{N} / 4$ minutes before the consumer wakes up where ' $\mathrm{N}$ ' is the amount of 
time needed to raise the temperature of the house to reach desired temperature in all 20 houses.

- It is noted that the load consumption is mostly uniform and the peak load is $22.5 \mathrm{~kW}$.

- Hence this optimized approach helped in reduce the peak load.

\begin{tabular}{cccccc}
\hline \multicolumn{5}{c}{ Optimized approach } \\
\hline Interval & Group no. & No of houses & Power rating & Time & Consumption \\
\hline $\mathbf{1}$ & 1 & 5 & (in KW) & $5: 20$ & \\
$\mathbf{2}$ & 2 & 5 & 4.5 & $5: 25$ & 22.5 \\
$\mathbf{3}$ & 1 & 5 & 4.5 & $5: 30$ & 22.5 \\
$\mathbf{4}$ & 3 & 5 & 4.5 & $5: 35$ & 22.5 \\
$\mathbf{5}$ & 2 & 5 & 4.5 & $5: 40$ & 22.5 \\
$\mathbf{6}$ & 1 & 5 & 4.5 & $5: 45$ & 22.5 \\
$\mathbf{7}$ & 4 & 5 & 4.5 & $5: 50$ & 22.5 \\
$\mathbf{8}$ & 3 & 5 & 4.5 & $5: 55$ & 22.5 \\
$\mathbf{9}$ & 2 & 5 & 4.5 & $6: 00$ & 22.5 \\
$\mathbf{1 0}$ & 1 & 5 & 4.5 & $6: 05$ & 22.5 \\
$\mathbf{1 1}$ & 4 & 1 & 4.5 & $6: 10$ & 22.5 \\
$\mathbf{1 2}$ & 3 & 2 & 4.5 & $6: 15$ & 4.5 \\
$\mathbf{1 3}$ & 2 & 3 & 4.5 & $6: 20$ & 9 \\
\hline $\mathbf{1 4}$ & 1 & 2 & 4.5 & $6: 25$ & 13.5 \\
\hline
\end{tabular}

Table 5 - The table shows the operating sequence of the HVAC system after implementing the optimization formulation

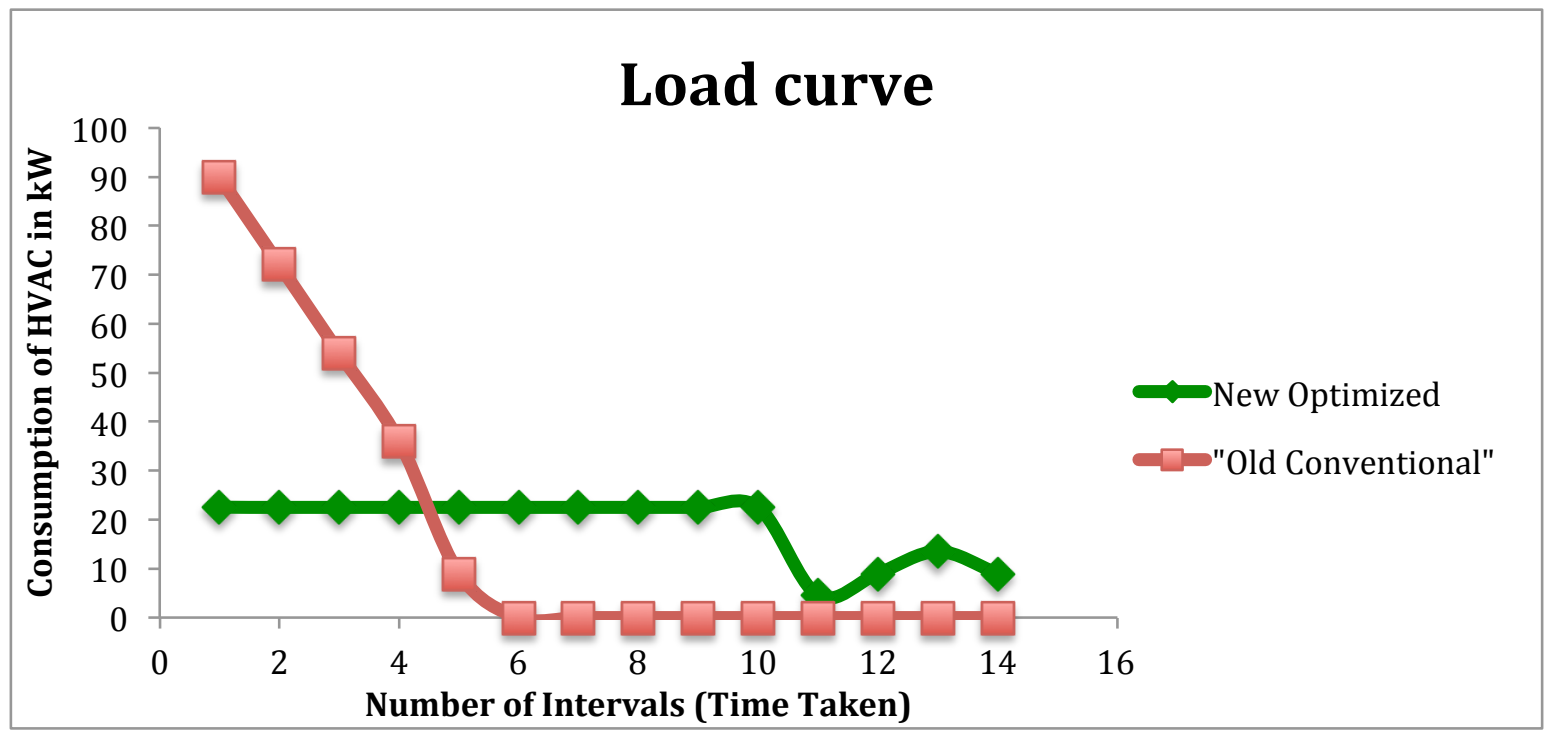

Graph 4 - Load profile comparison of traditional and optimized approach 
From the simulation comparison we note that the PD on the grid is nearly reduced by $75 \%$ as the HVAC sequence is changed to run over a larger timeframe to distribute the load without affecting consumer's comfort level. The new approach after being implemented reduces the PD by $75 \%$. As the maximum demand in the traditional old approach is $89 \mathrm{~kW}$ and the maximum demand in the new optimized approach is $22.5 \mathrm{~kW}$.

\subsubsection{Simulation results for case 2}

- In this case different house sizes and corresponding to that size different capacity/power rating of the HVAC system is considered.

- The houses considered are small (S), medium (M) and large (L) with HVAC power rating of $3.5 \mathrm{~kW}, 4.5 \mathrm{~kW}$ and $5.5 \mathrm{~kW}$ respectively.

- It is assumed that there is no heat loss in the house hence the temperature attained will remain the same.

\begin{tabular}{cccc}
\hline \multicolumn{4}{c}{ Non - Optimized approach (original/traditional) } \\
\hline Interval & No of houses & Time & $\begin{array}{c}\text { Consumption } \\
\text { (in KW) }\end{array}$ \\
\hline $\mathbf{1}$ & 20 & $6: 30$ & 89 \\
$\mathbf{2}$ & 16 & $6: 35$ & 70 \\
$\mathbf{3}$ & 12 & $6: 40$ & 54 \\
$\mathbf{4}$ & 8 & $6: 45$ & 36 \\
$\mathbf{5}$ & 2 & $6: 50$ & 8 \\
$\mathbf{6}$ & 0 & $6: 55$ & 0 \\
$\mathbf{7}$ & 0 & $7: 00$ & 0 \\
$\mathbf{8}$ & 0 & $7: 05$ & 0 \\
$\mathbf{9}$ & 0 & $7: 10$ & 0 \\
$\mathbf{1 0}$ & 0 & $7: 15$ & 0 \\
$\mathbf{1 1}$ & 0 & $7: 20$ & 0 \\
$\mathbf{1 2}$ & 0 & $7: 25$ & 0 \\
$\mathbf{1 3}$ & 0 & $7: 30$ & 0 \\
$\mathbf{1 4}$ & 0 & $7: 35$ & 0 \\
\hline
\end{tabular}

Table 6 - Part 2 case 2 non-optimized (traditional) way of HVAC operation 
- As seen from the table 6 above, which is the traditional approach, it is noted that the peak load is $89 \mathrm{~kW}$.

- As the intervals passes by the load consumption reduces as the houses reach their desired temperature.

\begin{tabular}{ccccc}
\hline \multicolumn{5}{c}{ Optimized approach } \\
\hline $\begin{array}{c}\text { Interva } \\
\text { I }\end{array}$ & Group no. & No of houses & Time & Consumption \\
& & & $5: 20$ am & (in kW) \\
$\mathbf{1}$ & 1 & 5 & $5: 25$ & 23.5 \\
$\mathbf{2}$ & 2 & 5 & $5: 30$ & 20.5 \\
$\mathbf{3}$ & 1 & 5 & $5: 35$ & 23.5 \\
$\mathbf{4}$ & 3 & 5 & $5: 40$ & 21.5 \\
$\mathbf{5}$ & 2 & 5 & $5: 45$ & 20.5 \\
$\mathbf{6}$ & 1 & 5 & $5: 50$ & 23.5 \\
$\mathbf{7}$ & 4 & 5 & $5: 55$ & 23.5 \\
$\mathbf{8}$ & 3 & 5 & $6: 00$ & 21.5 \\
$\mathbf{9}$ & 2 & 5 & $6: 05$ & 20.5 \\
$\mathbf{1 0}$ & 1 & 5 & $6: 10$ & 23.5 \\
$\mathbf{1 1}$ & 4 & 1 & $6: 15$ & 23.5 \\
$\mathbf{1 2}$ & 3 & 2 & $6: 20$ & 21.5 \\
\hline $\mathbf{1 3}$ & 2 & 3 & $6: 25$ & 20.5 \\
$\mathbf{1 4}$ & 1 & 2 & $6: 30$ & 23.5 \\
\hline
\end{tabular}

Table 7 - Part 2 case 2 optimized approach where the load is distributed over larger time

- In the table 7 above it is noted that the load consumption stays between $20.5 \mathrm{~kW}$ and $23.5 \mathrm{~kW}$ hence the peak load is $23.5 \mathrm{~kW}$ on the grid.

- The table 8 below shows that all the 20 houses are randomly allocated different size of the HVAC system corresponding to the house size.

- The houses are then sorted in ascending order of their thermostat temperature readings.

- And finally they are grouped in to 4 groups with each group consisting of 5 houses. 


\begin{tabular}{|c|c|c|c|c|c|c|c|}
\hline House & ${ }^{\circ} \mathrm{C}$ & Size & $\begin{array}{c}\mathbf{k W} \\
\text { rating }\end{array}$ & House & ${ }^{\circ} \mathrm{C}$ & Size & $\begin{array}{c}\text { KW } \\
\text { rating }\end{array}$ \\
\hline 1 & 16 & $S$ & 3.5 & 1 & 16 & $\mathrm{~S}$ & 3.5 \\
\hline 2 & 18 & M & 4.5 & 11 & 16 & M & 4.5 \\
\hline 3 & 17 & $\mathrm{~L}$ & 5.5 & 3 & 17 & $\mathrm{~L}$ & 5.5 \\
\hline 4 & 19 & $\mathrm{~S}$ & 3.5 & 6 & 17 & $\mathrm{~L}$ & 5.5 \\
\hline 5 & 20 & M & 4.5 & 8 & 17 & M & 4.5 \\
\hline 6 & 17 & $\mathrm{~L}$ & 5.5 & 13 & 17 & $\mathrm{~S}$ & 3.5 \\
\hline 7 & 18 & $S$ & 3.5 & 16 & 17 & S & 3.5 \\
\hline 8 & 17 & M & 4.5 & 18 & 17 & $\mathrm{~L}$ & 5.5 \\
\hline 9 & 20 & $\mathrm{~L}$ & 5.5 & 2 & 18 & M & 4.5 \\
\hline 10 & 19 & S & 3.5 & 7 & 18 & $\mathrm{~S}$ & 3.5 \\
\hline 11 & 16 & M & 4.5 & 12 & 18 & $\mathrm{~L}$ & 5.5 \\
\hline 12 & 18 & $\mathrm{~L}$ & 5.5 & 17 & 18 & M & 4.5 \\
\hline 13 & 17 & S & 3.5 & 4 & 19 & $S$ & 3.5 \\
\hline 14 & 19 & M & 4.5 & 10 & 19 & $\mathrm{~S}$ & 3.5 \\
\hline 15 & 20 & $\mathrm{~L}$ & 5.5 & 14 & 19 & M & 4.5 \\
\hline 16 & 17 & S & 3.5 & 20 & 19 & M & 4.5 \\
\hline 17 & 18 & M & 4.5 & 5 & 20 & M & 4.5 \\
\hline 18 & 17 & $\mathrm{~L}$ & 5.5 & 9 & 20 & $\mathrm{~L}$ & 5.5 \\
\hline 19 & 20 & $S$ & 3.5 & 15 & 20 & $\mathrm{~L}$ & 5.5 \\
\hline 20 & 19 & M & 4.5 & 19 & 20 & $S$ & 3.5 \\
\hline
\end{tabular}

Table 8 - Pink table - Randomly allocated size of the house, Green table - Houses sorted in ascending order of temperature reading and Blue tables below show the grouping of the houses.

\begin{tabular}{|c|c|c|c|}
\hline \multicolumn{4}{|c|}{ Group 1 } \\
\hline House & ${ }^{\circ} \mathrm{C}$ & Size & Rating \\
\hline $\mathbf{1}$ & 16 & $\mathrm{~S}$ & 3.5 \\
\hline $\mathbf{1 1}$ & 16 & $\mathrm{M}$ & 4.5 \\
\hline $\mathbf{3}$ & 17 & $\mathrm{~L}$ & 5.5 \\
\hline $\mathbf{6}$ & 17 & $\mathrm{~L}$ & 5.5 \\
\hline $\mathbf{8}$ & 17 & $\mathrm{M}$ & 4.5 \\
\hline
\end{tabular}

\begin{tabular}{|c|c|c|c|}
\hline \multicolumn{5}{|c|}{ Group 2 } \\
\hline House & ${ }^{\circ} \mathrm{C}$ & Size & Rating \\
\hline $\mathbf{1 3}$ & 17 & $\mathrm{~S}$ & 3.5 \\
\hline $\mathbf{1 6}$ & 17 & $\mathrm{~S}$ & 3.5 \\
\hline $\mathbf{1 8}$ & 17 & $\mathrm{~L}$ & 5.5 \\
\hline $\mathbf{2}$ & 18 & $\mathrm{M}$ & 4.5 \\
\hline $\mathbf{7}$ & 18 & $\mathrm{~S}$ & 3.5 \\
\hline
\end{tabular}

\begin{tabular}{|c|c|c|c|}
\hline \multicolumn{4}{|c|}{ Group 3 } \\
\hline House & ${ }^{\circ} \mathrm{C}$ & Size & Rating \\
\hline $\mathbf{1 2}$ & 18 & L & 5.5 \\
\hline $\mathbf{1 7}$ & 18 & M & 4.5 \\
\hline $\mathbf{4}$ & 19 & S & 3.5 \\
\hline $\mathbf{1 0}$ & 19 & S & 3.5 \\
\hline $\mathbf{1 4}$ & 19 & M & 4.5 \\
\hline
\end{tabular}

\begin{tabular}{|c|c|c|c|}
\hline \multicolumn{4}{|c|}{ Group 4 } \\
\hline House & ${ }^{\circ} \mathrm{C}$ & Size & Rating \\
\hline $\mathbf{2 0}$ & 19 & M & 4.5 \\
\hline $\mathbf{5}$ & 20 & $\mathrm{M}$ & 4.5 \\
\hline $\mathbf{9}$ & 20 & $\mathrm{~L}$ & 5.5 \\
\hline $\mathbf{1 5}$ & 20 & L & 5.5 \\
\hline $\mathbf{1 9}$ & 20 & $\mathrm{~S}$ & 3.5 \\
\hline
\end{tabular}




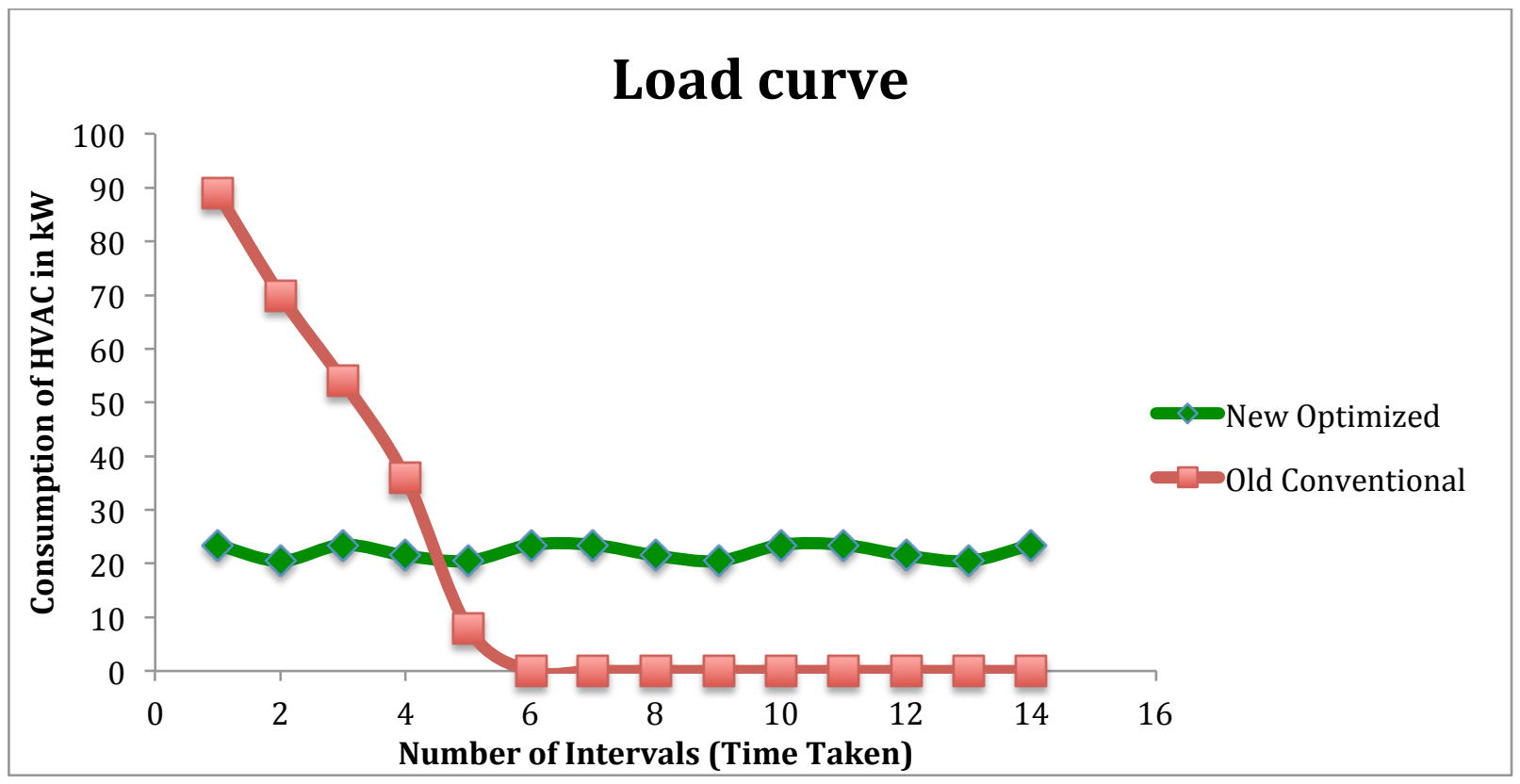

\section{Graph 5 - Load profile comparison of traditional way of HVAC operation and optimized approach of HVAC operating sequence for Part 2 case 2}

From simulation comparison results we note that if the size of the houses are different the load profile is bit wavy but still nearly $74 \%$ reduction in PD can be seen. As the maximum demand in the traditional old approach is $89 \mathrm{~kW}$ and the maximum demand in the new optimized approach is $23.5 \mathrm{~kW}$.

\subsubsection{Simulation results for case 3}

The HVAC run-time sequence is the same as that in case 2 . The only difference is the addition of heat loss compensation that is done by running a portion of HVAC after it raises the temperature of the house by $1^{\circ} \mathrm{C}$.

For the small houses it takes about 25 minutes to lose the temperature of the house by $1^{\circ} \mathrm{C}$ due to heat loss. So to compensate for the heat loss and to keep the temperature of the house at constant level the HVAC in small houses will turn ON at $20 \%$ capacity.

Similarly for medium houses the HVAC will turn ON at $25 \%$ capacity and for large houses the 
HVAC turn ON at $30 \%$ only a particular group stays off for more than two intervals.

We assume that major heat loss occurs in the later portion of the time i.e. for large house major heat loss occurs in the last 5 minutes and so on for other two houses.

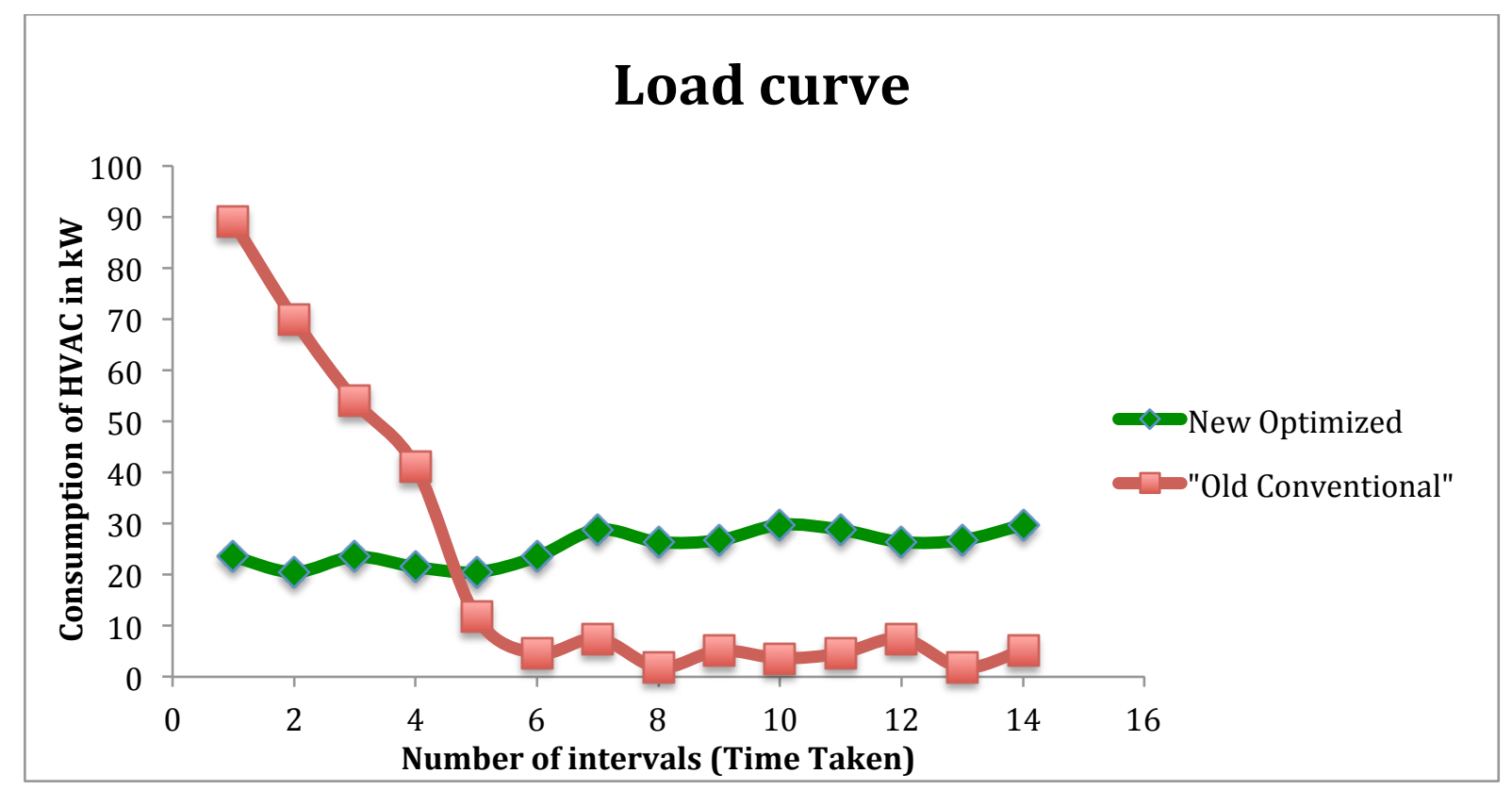

\section{Graph 6 - Load profile comparison of traditional way of HVAC operation and optimized approach of HVAC operating sequence for Part 2 case 3}

From the simulation comparison results we note that if the size of the houses are different with different insulation levels then the load profile is a bit wavy but still nearly $67 \%$ reduction in PD can be seen. As the maximum demand in the traditional old approach is $89 \mathrm{~kW}$ and the maximum demand in the new optimized approach is $29.5 \mathrm{~kW}$. In this case even the traditional approach has to compensate the heat loss. Hence, the red line is wavy, which shows some consumption to compensate the heat loss after all the houses reach their desired temperature. 


\section{Chapter - 6}

\section{CONCLUSION}

In this project, we have analyzed different approaches to Demand Side Management in the Smart Grid also we understood different problems faced by these mechanisms in managing the loads at the consumer end. We proposed a unique DSM strategy that manages both schedulable loads and non-schedulable loads. Different cases are presented to cope up with the needs of the consumer and the utility can have a better command on the grid. Overall this approach reduces the PD on the grid. Certain constraints are defined so that utility can limit the consumption to maintain reliability of the grid at the same time the consumer can benefit by saving money on electricity bills.

A distributed load DSM technique is defined for the Non-schedulable loads like HVAC system or refrigeration. As these loads stay in the $\mathrm{ON}$ state for most of the time it is very crucial to manage their run time to reduce the PD. Hence the overall runtime of the HVAC system is distributed over a large timeframe. We compared the simulation results with the traditional or conventional results and also with the other DSM approaches. We found that the proposed technique can reduce the PD on the grid up to $75 \%$ depending on the scenario. It is more efficient and reliable and does not interfere with the consumer's comfort level at all. 


\section{REFERENCES}

[1] Ali, S., Maqbool, S., Ahamed, T., \& Malik, N. (23-24 Aug 2013). Load scheduling with maximum demand and time of use pricing for microgrids. Global Humanitarian Technology Conference: South Asia Satellite (GHTC-SAS) (pp. 234-238). Trivandrum: IEEE.

[2] Soliman, H., \& Leon-Garcia, A. (May 2014). Game-Theoretic Demand-Side Management With Storage Devices for the Future Smart Grid. IEEE Transactions on Smart Grid. 5, pp. 1475-1485. IEEE.

[3] Fadlullah, Z., Quan, D. M., Kato, N., \& Stojmenovic, I. An Optimized Game-Theoretic Demand-Side Management Scheme for Smart Grid. IEEE systems journal. 8, no 2, pp. 588597. IEEE.

[4] Wijaya, T., Larson, K., \& Aberer, K. (7-10 Jan 2013). Matching demand with supply in the smart grid using agent-based multiunit auction. Fifth International Conference on Communication Systems and Networks (COMSNETS) (pp. 1-6). Bangalore: IEEE.

[5] Rahman, S., \& Rinaldy. (Aug 1993). An efficient load model for analyzing demand side management impacts. IEEE Transactions on Power Systems , 8 (3), 1219-1226.

[6] Cohen, A. I., \& Wang, C. (May 1988). An optimization method for load management scheduling. IEEE Transcations on Power Systems , 3 (2), 612-618.

[7] Ma, J., Deng, J., Song, L., \& Han, Z. (May 2014). Incentive mechanism for demand side management in smart grid using auction. IEEE Transactions on Smart Grid , 5 (3), 1379-1388. 
[8] Mohsenian-Rad, A.-H., Wong, V., Jatskevich, J., \& Schober, R. (Jan 2010). Optimal and autonomous incentive-based energy consumption scheduling algorithm for smart grid. Innovative Smart Grid Technologies (ISGT) (pp. 1-6). Gaithersburg, MD: IEEE.

[9] Cheah, P., Zhang, R., Gooi, H., Yu, H., \& Foo, M. (12-14 Dec 2012). Consumer energy portal and home energy management system for smart grid applications. IPEC, 2012 Conference on Power \& Energy (pp. 407-411). Ho Chi Minh City: IEEE.

[10] Han, D.-M., \& Lim, J.-H. (Aug 2010). Design and implementation of smart home energy management systems based on zigbee. IEEE Transactions on Consumer Electronics , 56 (3), 1417-1425.

[11] Ng, K.-H., \& Sheble, G. (May 1998). Direct load control-A profit-based load management using linear programming. IEEE Transactions on Power Systems , 13 (2), 668-694.

[12] Schweppe, F., Daryanian, B., \& Tabors, R. (May 1989). Algorithms for a spot price responding residential load controller. Power Engineering Review , 4 (2), 507-516.

[13] Li, Q. and Zhou M., (2011). “The future-oriented grid-smart grid,” . IEEE Transcations on Smart Grid , 6 (1), 98-105.

[14] Logenthiran, T., Srinivasan, D., \& Shun, T. Z. (Sept 2012). Demand Side Management in Smart Grid Using Heuristic Optimization. IEEE Transactions on Smart Grid , 3 (3), 12441252.

[15] Ipakchi, A., \& Albuyeh, F. (March-April 2009). Grid of the future . IEEE Power \& Energy Magazine , 7 (2), 52-62.

[16] Roscoe, A. and Ault G., (July 2010). Supporting high penetrations of renewable generation via implementation of real-time electricity pricing and demand response. Renewable Power Generation, IET , 4 (4), 369 - 382. 
[17] Khomami, H., \& Javidi, M. (1-3 Nov 2013). An efficient home energy management system for automated residential demand response. 13th International Conference on Environment and Electrical Engineering (EEEIC) (pp. 307 - 312). Wroclaw: IEEE.

[18] Wang, D., Ge, S., Jia, H., Wang, C., Zhou, Y., Lu, N., et al. (April 2014). A tie-line power smooth- ing method for microgrid using residential thermostatically-controlled loads. IEEE Transactions on Sustainable Energy , 5 (2), 476-486.

[19] I.K., M. (2010). Demand Side Management: Load Management, Load Profiling, Load Shifting, Residential and Industrial Consumer, Energy Audit, Reliability, Urban, Semi-Urban and Rural Setting. Saar-brucken, Germany: Lambert academic.

[20] D.P., K. (2003). Modern Power System Analysis. New Delhi, India: Tata McGraw-Hill.

[21] Zhu, Z., Tang, J., Lambotharan, S., Chin, W. H., \& Fan, Z. (16-20 Jan. 2012). An integer linear programming based optimization for home demand-side management in smart grid. Innovative Smart Grid Technologies (ISGT), 2012 IEEE PES (pp. 1-5). IEEE.

[22] Logenthiran, T., Srinivasan, D., \& Shun, T. Z. (Sept 2012). Demand Side Management in Smart Grid Using Heuristic Optimization. IEEE Transactions on Smart Grid , 3 (3), 1244 1252.

[23] Mohsenian-Rad, A.-H., Wong, V., Jatskevich, J., Schober, R., \& Leon-Garcia, A. (Dec 2010). Autonomous Demand-Side Management Based on Game-Theoretic Energy Consumption Scheduling for the Future Smart Grid. IEEE Transactions on Smart Grid , 1 (3), 320-331.

[24] Zhu, Z., Tang, J., Lambotharan, S., Chin, W., \& Fan, Z. (5-9 Dec 2011). An integer linear programming and game theory based optimization for demand-side management in smart grid. GLOBECOM Workshops (GC Wkshps), 2011 IEEE (pp. 1205 - 1210). Houston ,TX: IEEE. 
[25] Nguyen, H. K., Song, J., \& Han, Z. (25-30 March 2012). Demand side management to reduce Peak-to-Average Ratio using game theory in smart grid. IEEE Conference on Computer Communications Workshops (INFOCOM WKSHPS), 2012 (pp. 91 - 96). Orlando, FL: IEEE.

[26] Samadi, P., Mohsenian-Rad, H., Schober, R., \& Wong, V. (Sept. 2012). Advanced demand side management for the future smart grid using mechanism design. IEEE Transactions on Smart Grid, , 3 (3), 1170 - 1180.

[27] Edison tech center, (2013). The history of Electricifrication: The birth of our Power Grid. USA.

[28] Kaplan S.M., (2009). Smart Grid. Electrical Power Transmission: Background and Policy Issues. The capital Net Government series.

[29] Agency, I. E. (2012). World Energy Outlook. IEA.

[30] Yan, Y., Qian, Y., Sharif, H., \& Tipper, D. (2013). A survey on smart grid communication infrastructures: Motivations, requirements and challenges. IEEE Communications Surveys \& Tutorials , 15 (1), 5 - 20.

[31] Ma, R., Chen, H.-H., Huang, Y.-R., \& Meng, W. (March 2013). Smart grid communication: Its challenges and opportunities. IEEE Transactions on Smart Grid , 4 (1), 36 $-46$.

[32] Ye, F., Qian, Y., \& Hu, R. (Jan. 2015). Energy efficient self-sustaining wireless neighborhood area network design for smart grid. IEEE Transactions on Smart Grid , 6 (1), 220-229. 
[33] Zhou, J., Hu, R., \& Qian, Y. (Sept. 2012). Scalable distributed communication architectures to support advanced metering infrastructure in smart grid. IEEE Transactions on Parallel and Distributed Systems , 23 (9), 1632 - 1642.

[34] Gharavi, H., \& Xu, C. (June 2012). Traffic scheduling technique for smart grid advanced metering applications. IEEE Transactions on Communications , 60 (6), 1646 - 1658.

[35] Yan, Y., Qian, Y., \& Sharif, H. (Dec 2011). A Secure Data Aggregation and Dispatch Scheme for Home Area Networks in Smart Grid. Global Telecommunications Conference (GLOBECOM 2011) (pp. 1 - 6). Houston, TX, USA: IEEE.

[36] Yujie, L., Peilin, L., \& Jing, L. (25-28 March 2011). A Realities Model Simulation Platform of Wireless Home Area Network in Smart Grid. Power and Energy Engineering Conference (APPEEC), 2011 Asia-Pacific (pp. 1 - 4). Wuhan: IEEE.

[37] Iwayemi, A., Yi, P., Dong, X., \& Zhou, C. (2011). Knowing when to act: an optimal stopping method for smart grid demand response. IEEE Network: The Magazine of Global Internetworking , 25 (5), 44-49.

[38] William P., J. A. (1991). Algorithms for slab on grade heat transfer calculations. 


\section{GLOSSARY}

GRID - An electrical grid is an interconnected network for delivering electricity from suppliers to consumers. It consists of generating stations that produce electrical power, high-voltage transmission lines that carry power from distant sources to demand centers, and distribution lines that connect individual customers. [1]

PEAK DEMAND / MAXIMUM DEMAND - The maximum load seen on the electrical grid throughout the day is termed as the Peak Demand.

PEAK TO AVERAGE RATIO - The peak-to-average power ratio (PAR) is the peak amplitude squared (giving the peak power) divided by the RMS value squared (giving the average power).

DEMAND SIDE MANAGEMENT - It is defined as the modification of consumer demand for energy through various methods such as financial incentives and behavioral change through education. [2]

DEMAND RESPONSE - Changes in electric usage by end-use customers from their normal consumption patterns in response to changes in the price of electricity over time, or to incentive payments designed to induce lower electricity use at times of high wholesale market prices or when system reliability is jeopardized. [3]

HOME ENERGY MANAGEMENT SYSTEM - A combination of wireless sensors, smart appliances that communicate with each other and are connected to a central controller in a house is known as Home Energy Management System. 
TIME OF USE TARIFF - Time-based pricing or Time of use tariff is a pricing strategy where the provider of a service or supplier of a commodity, may vary the price depending on the time-of-day when the service is provided or the commodity is delivered.

BLACK OUT / BROWN OUT - A blackout is a complete interruption of power in a given service area and a brownout is an intentional or unintentional drop in voltage in an electrical power supply system.

LOAD SHEDDING - It is an intentionally engineered electrical power shutdown where electricity delivery is stopped.

SMART GRID - A smart grid is an electrical grid, which includes a variety of operational, and energy measures including smart meters, smart appliances, renewable energy resources, and energy efficiency resources. [4]

ON-PEAK - The period of the day when the load demand on the grid is highest.

OFF-PEAK - The period of the day when the load demand on the grid is the lowest.

MID-PEAK - The period of the day when the load demand on the grid is at intermediate level.

SMART METERS - A smart meter is usually an electronic device that records consumption of electric energy in intervals of an hour or less and communicates that information at least daily back to the utility for monitoring and billing. Smart meters enable two-way communication between the meter and the central system. [5]

HOME AREA NETWORK - It is a wireless network at house level, which acts as an interface between the smart appliances and the smart controller or smart meter.

SMART APPLIANCES - A smart appliance is a state-of-the-art device that connects to the smart controller or smart meter to give you more information and control than ever before. 
R-VALUE - Insulation level of a material or a surface is denoted in R-value i.e. thermal resistance value of that material.

ENERGY CONSUMPTION SCHEDULER / ENERGY CONSUMPTION CONTROLLER -

They are also known as smart controller that acts as an interface between the utility and the consumer. 